TPeriodica Polytechnica Civil Engineering

62(2), pp. 517-532, 2018

https://doi.org/10.3311/PPci.11304

Creative Commons Attribution (i)

RESEARCH ARTICLE

\section{Numerical Investigation into the Ultimate Strength of Steel Cellular Beams with Semi-Rigid Connections}

\author{
Abdelhalim Madjour ${ }^{1 *}$, Mohamed Rédha Soltani ${ }^{1}$, El Haddi Harkati ${ }^{1}$
}

Received 24 July 2017; Revised 24 October 2017; Accepted 27 November 2017

\begin{abstract}
Over the past several years, extensive theoretical, numerical and experimental research has been carried out on the structural behavior of steel beams with web openings of various shapes. However, in all these studies, cellular beams have always been treated or designed as simply supported at their ends. In other words, the beam to column connections are assumed as nominally pinned. The main aim of the present paper is to perform numerical simulations to determine whether the use of end plate connections, instead of simple connections, could enhance the global bending and/or shear capacity of cellular beams with circular and sinusoidal web openings.

Interaction between a circular or sinusoidal opening in the beam web and endplate connection has also been studied. Data obtained from a number of experimental research programs on steel solid beam to column connections and simply supported cellular beams, available in the literature, were utilized to validate the numerical models developed in this paper. The numerical simulations using ABAQUS software were performed on full scale cellular steel beams connected to the columns with seven types of endplate connections. The results were compared with those obtained for similar simply cellular beams.
\end{abstract}

\section{Keywords}

endplate connection, cellular beams, pinned connections, circular openings, sinusoidal openings, ultimate load

\section{Introduction}

Throughout the last several decades, cellular beams have been used extensively in steel construction to pass under-floor services ducts (water and sewage pipes, air ducts, cables etc.) and for their aesthetic and design advantages.

The process of manufacturing cellular beams consists of cutting the web of the parent profile by flame in a zigzag pattern along its centerline. The two obtained T-sections are shifted and rewelded producing beams with hexagonal, circular or sinusoidal openings and lead to an increase in height compare to the parent profile. Cellular beams with sinusoidal openings called Angelina are fabricated only by using one oxycutting line instead of two for the standard perforated beams with regular circular or hexagonal openings. By increasing the depth of the beam, the strong axis bending strength and stiffness are improved without increasing the weight of the beam allowing this type of beams to be used for medium to long spans constructions. The digital and parallel fabrication processes reduces considerably the cost of cellular beams.

In the current structural European design codes [1-3], steel or composite cellular beams have always been designed as simply-supported at their ends. Simple connections, which are classified as nominally pinned that are assumed to transmit end shear only and to have negligible resistance to rotation, are used. Fin plates, double angle web, and partial end plates beam to column connections are commonly classified as nominally pinned. Typical examples of these connections types are shown in Fig. 1.

a)
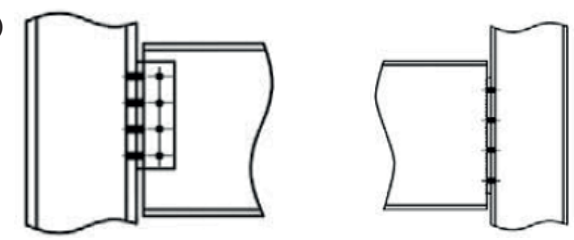

b)

c)

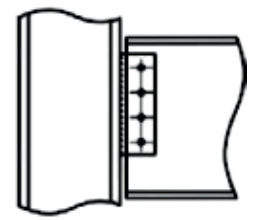

a) Partial depth end plate b) Double angle cleats c) Fin plate Fig. 1 Commonly used simple beam-to-column connections 
The main aim of the present paper is to determine through numerical simulations whether the use of rigid or semi-rigid joints, instead of pinned joints, could enhance the global bending and/or shear capacity of cellular beams with circular and sinusoidal openings. The effect of the web openings on the connection moment-relative rotation curves is also studied. Analysis simulations were performed using the commercial finite element analysis software ABAQUS, version 6.14. Data obtained from a number of experimental research programs on steel beam to column connections and simply supported cellular beams, available in the literature, were utilized to validate the numerical models developed in this research.

The behaviour of a joint is represented by moment-rotation curve relating the moment transmitted by the joint to the relative rotation between the members it connects [4]. The numerical or experimental nonlinear moment-rotation curves are generally in practice approximate with bilinear response as shown in Fig. 2. They are characterized by the following features $[11,12]$ : the knee-range of the M- $\phi$ curve, the plastic flexural resistance, $M_{j . R d}$, the maximum bending moment, $M_{\max }$, the initial stiffness, $S_{j . i n i}$, the post-limit stiffness, $S_{j . p-1}$, the rotation corresponding to the maximum load level, $M_{\max }$ and the rotation capacity, $\phi_{\mathrm{Cd}}$. The main features of this curve, as specified in Eurocode 3, part 1.8 [5], are: the initial stiffness, $\mathrm{S}_{\mathrm{j} \text {.ini }}$, the moment resistance of the joint, $\mathrm{M}_{\mathrm{j} . \mathrm{Rd}}$, and the capacity of rotation (ductility).

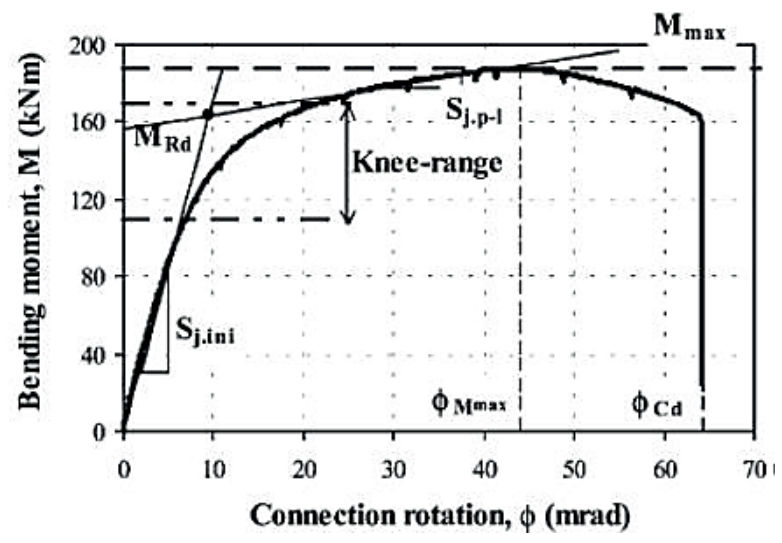

Fig. 2 Moment-rotation curves [12]

The current component method introduced in EN 1993-1-8 [5] can be used for the characterization of beam-to-column joints subjected to bending moment and axial forces. The main principle of the component method consists of dividing the end plate connection into basic components, including the panel zone, bolt, end plate and column flange. Its application requires the evaluation of the force-deformation response of each individual component which depends on mechanical and geometrical properties of the joint components. The properties of each component allow the specification of the corresponding moment-rotation curve and the associated properties (stiffness and moment resistance).
The initial rotational stiffness of the end-plate bolted joints is given by a mechanical model composed of several extensional springs and rigid links, each one representing a component of the joint.

The moment resistance of bolted end plate joint is governed by the resistance of one of the following:

- the column web panel in shear; the column web in compression; the column web in tension; the column flange in bending; the beam end plate in bending; the beam flange and web in compression; the beam web in tension; bolts in tension; bolts in shear; welds.

Joints are classified by stiffness and by strength according to the global analysis used. When elastic analysis is used, the joints are classified according to their stiffness. When rigid plastic analysis is used, the joints are classified according to their strength (moment capacity). When elastic-plastic analysis is used, both classifications are used.

A joint in a frame able to preserve the original angle between the connected members is classified as rigid. The connection is classified as simple if it rotates without increasing moment. The connection stiffness between these two boundaries is categorised as a partially restrained or semi-rigid connection. In this respect, clause 5.2.2 of EC3-1-8 [5] classifies as rigid if $\mathrm{S}_{\mathrm{j} \text {.ini }} \geq \mathrm{k}_{\mathrm{b}}$ $\mathrm{EI}_{\mathrm{b}} / \mathrm{L}_{\mathrm{b}}$ where $\mathrm{EI}_{\mathrm{b}}$ is the flexural rigidity of the beam connected, $\mathrm{L}_{\mathrm{b}}$ its length and $\mathrm{k}_{\mathrm{b}}=8$ for frames where the bracing system reduces the horizontal displacement by at least $80 \% ; \mathrm{k}_{\mathrm{b}}=25$ for other frames. A joint may be classified as nominally pinned if $\mathrm{S}_{\mathrm{j} \text {.ini }} \leq 0.5 \mathrm{EI}_{\mathrm{b}} / \mathrm{L}_{\mathrm{b}}$.

A joint which cannot be classified as either nominally pinned or rigid is classified as rigid.

Clause 5.2.3 of EC3-1-8 [5] classifies frame joints as fullstrength, nominally pinned or partial strength by comparing their design moment resistance with the design moment resistances of the members that it connects. A joint may be classified as nominally pinned if its design moment resistance is not greater than 0.25 times that required for a full strength joint, provided it has sufficient rotation capacity. A joint which cannot be classified as either nominally pinned or full strength is classified as partial strength. The purpose of this classification is to determine whether the joint or one of the connected members will limit the resistance of the frame.

Concerning the seismic behaviour of joints, numerous studies [6-10] have shown that weakening plain beams by making a single or a number of openings through their webs in the vicinity of joints move the plastic hinge in the beam away from the joint improving the connection ductility (rotation capacity).

\section{Experimental tests used for the validation of the numerical models}

Numerical models are required to be carefully validated against experimental data in order to determine the accuracy of the modeling. As mentioned above, the aim of this study is 
to investigate whether steel perforated beams connected to a column with extended end plate will have higher resistance than their simply supported counterparts. Since all experimental test results reported in the literature concern simply supported cellular beams, selected experimental data found in the literature on plain-webbed beam to column endplate bolted connections and simply supported cellular beams with circular and sinusoidal openings were used to validate the numerical model used to simulate the behavior of partially restrained cellular beams considered in this study.

The finite element model proposed for the simulation of bolted end plate connections was validated by comparing the numerical results, in terms of moment-rotation curves, with those of tests, performed on four bolted connection test specimens.

The test specimens J1.1, J3.1 and J4.1 consisting of external double extended bolted endplate single-sided beam to column joints were tested by Nogueiro [13] at Coimbra University. The specific details of the testing program were also described in reference [14]. The configurations of the joints differ mainly in the column and beam cross sections. For all cases, $18 \mathrm{~mm}$ thick endplates were chosen, connected to the beam-ends by full strength $45^{\circ}$ continuous fillet welds. The column is $3 \mathrm{~m}$ long, hinged at the bottom to a concrete block and had a free vertical displacement at the top. A typical joint's detail is shown in Fig. 3.

The measured mechanical properties of the joint components were obtained from uniaxial tensile tests performed on coupons, extracted from the beams, the columns, the end plates, and from some bolts. The loading was applied monotonically in a displacement-controlled procedure. Equations were used to estimate the experimental rotations from the vertical displacements of the beam and the horizontal displacements of the end plates which were measured by means of displacement transducers fixed at appropriate locations.
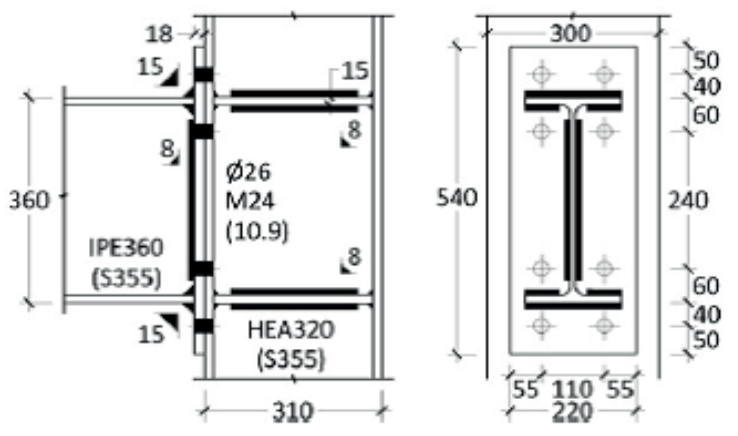

Fig. 3 Detail of the joint J1.1 [14]

The fourth specimen $\mathrm{BC} 1$ is an interior sub-assemblage consisting of two beams connected to opposite flange of a single column with two extended end plates. This specimen is one of the four specimens tested by Abidelah and Bouchair [15] at Blaise Pascal University. The beam and the column were made of IPE 240 and HEA 120 hot rolled profiles, respectively. The endplate had a thickness of $15 \mathrm{~mm}$. The steel of all components is of class S235 steel grade. The beam is connected to the column with three rows of bolts. The connection had two high tension bolts M16 per horizontal row with grade 8.8 in 18 $\mathrm{mm}$ drilled holes. The material properties of the steel and bolts were obtained from tensile coupon tests taken from the main components of the test specimen. A vertical load was applied to the upper end of the column by one hydraulic actuator and was monotonically increased under displacement control at the rate of $0.02 \mathrm{~mm} / \mathrm{s}$. Different devices were used to measure displacements and rotations in the connection zone. The test setup and the location of the measuring devices used by Abidelah and al [15] are illustrated in Fig. 4.

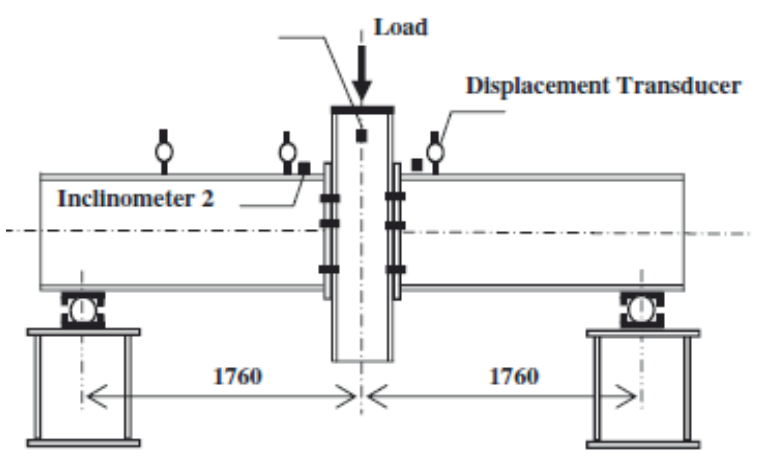

Fig. 4 Test setup and location of the measuring devices [15]

For perforated beams, the outputs of the numerical simulations were validated using experimental measurements published by Warren [16] and Durif [17,18]. The test specimens denoted 1A, $2 \mathrm{~A}$, and $2 \mathrm{~B}$ were part of eight cellular beams tested by Warren [16] at Natal University. These specimens were fabricated from hot rolled I-sections UB $203 \times 133 \times 25$. Specimens 1 A and $2 A$ were subjected to a single point load, whereas specimen $2 \mathrm{~B}$ was loaded with two equal and symmetrical point loads. The spans and the ratios of the opening spacing to the opening diameter of the tested beams, 1.5 for beams $1 \mathrm{~A}$ and 1.33 for beams $2 \mathrm{~A}$ and $2 \mathrm{~B}$, were chosen to avoid failure by premature web-post buckling or shearing. Lateral supports were provided to the compression flange to prevent lateral-torsional buckling. A typical test setup used by Warren [16] is shown in Fig. 5

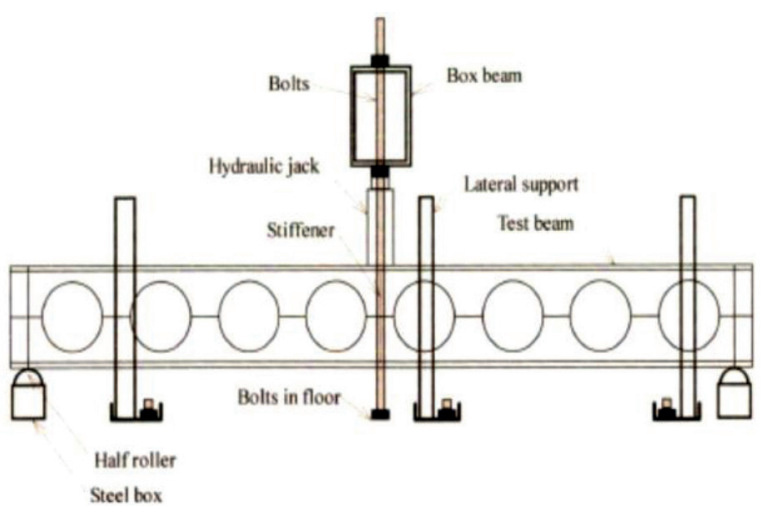

Fig. 5 Example of test setup used by Warren [16] 
Three full scale cellular beams with six regular spaced sinusoidal web openings (Angelina beams), denoted ASO12, ASO16 and ASO18, were tested by Durif and Bouchair [16,17] at Blaise Pascal University. Beams ASO12 and ASO16 were made from a hot rolled IPE 450 in S460 and S235 steel grades respectively, while beam SO18 was made from an IPE 400 in S460 steel grade. In order to obtain different modes of failure, various sizes of web openings were adopted. Initial geometric imperfections were measured for the three test beams. A four point bending test set-up was used as illustrated in Fig. 6.

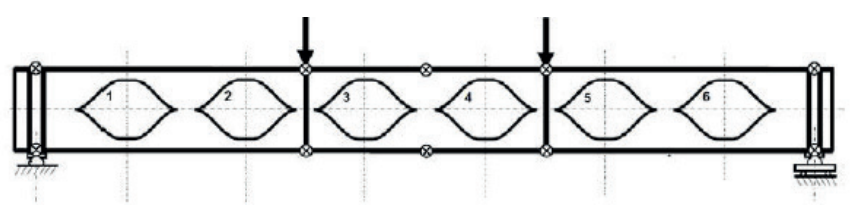

Fig. 6 Loading and lateral support conditions [17]

\section{Development and validation of finite element models for joint connections and simply supported castellated beams}

The purpose of this section is to develop and validate two numerical models that have the ability to simulate accurately the moment-rotation response of bolted end plate connections and the flexural response of simply supported cellular beams. The numerical simulations were performed for the specimens, tested in the experimental programs described above, by using the general purpose finite element software Abaqus, ver. 6.14 [19]. Material nonlinearities, large deflection, large strain and contact between different joint surfaces were included in the models.

All the models were meshed with eight-node linear brick elements with reduced integration (1 Gauss point) and an hourglass control using the artificial stiffness method and hybrid formulation (C3D8RH). This element has three translational degree-of-freedoms per node and has the ability to deal with problems that involve contact, plasticity, and large deformations. For the endplate joint specimens, the nut, the bolt-head, and the two washers placed on both ends of the bolt (nut and bolt-head) were meshed as a single body. The density, the configuration and the number of layers across the thickness of the finite element mesh for each specimen were determined based on the results obtained from convergence studies in order to provide a reasonable balance between accuracy and computational expense. For each specimen, different mesh densities were adopted according to stress concentration. Four layers of solid elements were needed to obtain results with enough accuracy for the bolted joints, while convergence was achieved by using one layer of solid elements for the simply supported cellular beams. Overall views of typical finite element models used in this study are shown in Fig. 7, 8 et 9.

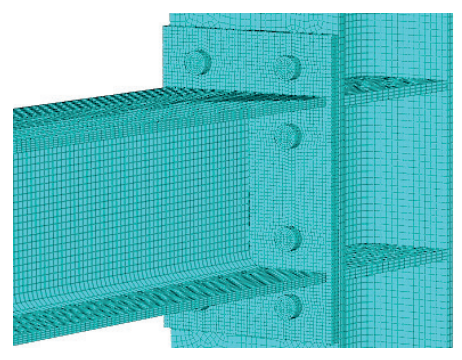

a) Global

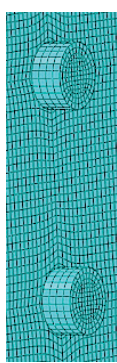

b) end plate detail

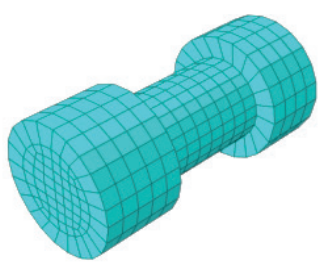

c) bolt detail

Fig. 7 Typical finite element mesh of end plate steel connection

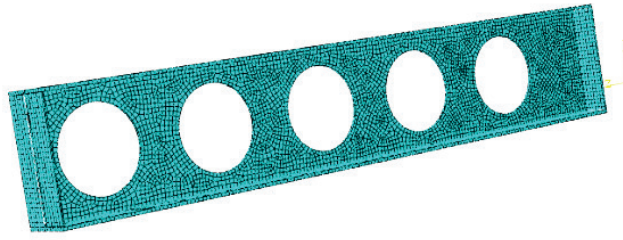

Fig. 8 Typical Finite element mesh of cellular beam with circular openings

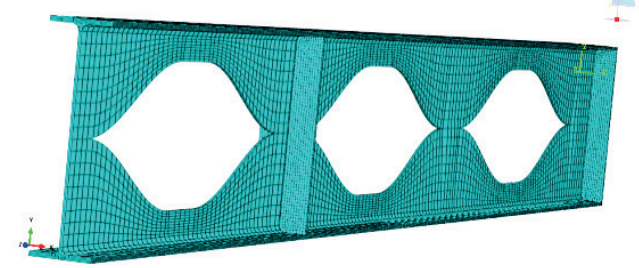

Fig. 9 Typical Finite element mesh of cellular beam with sinusoidal openings

In addition to the meshing, the proposed numerical models have to be calibrated according to the nonlinear properties of the contact surfaces and the stress-strain constitutive law which describes the uniaxial material response of each of the components of the specimens.

The interaction between the column flange and the back of the end plate was modeled using surface-to-surface contact 3-D elements having tangential and normal behaviors. The tangential contact was defined with a frictional contact of 0.3 using the penalty stiffness formulation. The normal contact was defined with hard contact using augmented Lagrange formulation. The welded regions were not explicitly modeled. Nevertheless, they were modeled as part of the beam or the column material. Tie constrain algorithm was used to simulate the behavior of the welding regions that connects the end beam to the endplate and eventually the stiffeners to the column. The bolt head, completely fixed to the bolt shank, and the nut were modeled as steel cylinders. They were tied constraint to the back of the end plate/column flange by using the tie constraint 


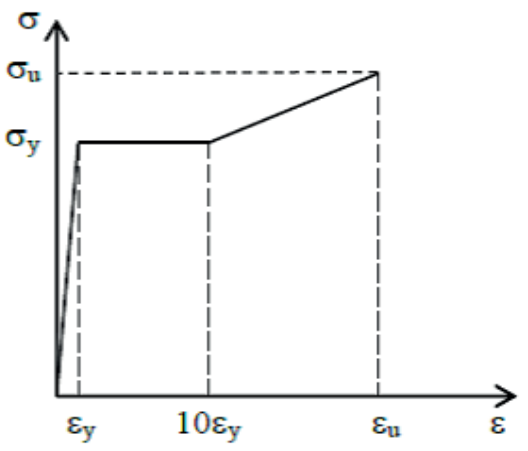

a) Columns, beams and end plates

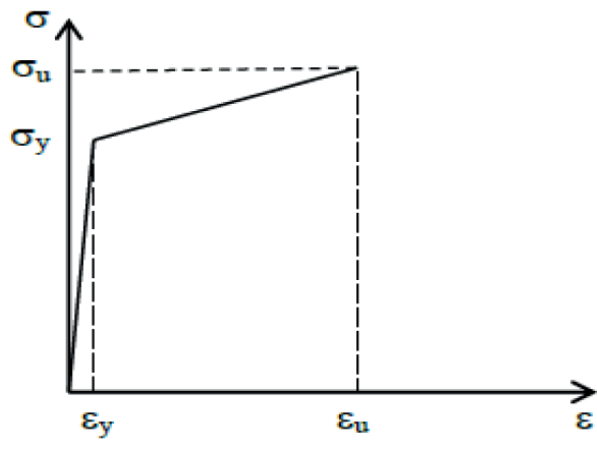

b) Bolts

Fig. 10 Material stress-strain curves used for numerical analyses

parameter. Tie constraints are used to tie together two surfaces for the duration of a simulation. They are particularly useful for rapid mesh refinement between dissimilar meshes. Contact between the bolt shank and the inside of the bolt hole was considered as frictionless.

A tri-linear elastic-plastic uniaxial stress-strain curve for the connection components and for the cellular beams was used to simulate the material behaviour of steel in both tension and compression as depicted in Fig. 10(a). A bilinear stress strain relationship was utilized for the high-strength bolts as shown in Fig. 10(b). The points defining the stress-strain curves are taken from the test data given in references [14-18]. The Von Mises yield criterion was used in conjunction with the Prandtl-Reuss associated flow rule to determine the onset of yielding and the amount of incremental plastic strain. In Abaqus, the material response to unidirectional stress is input through $\sigma_{t}$ vs. $\varepsilon_{t}$, the true stress and the true strain respectively which account for large strains, where:

$$
\begin{gathered}
\sigma_{t}=\sigma_{n}\left(1+\varepsilon_{n}\right) \\
\varepsilon_{t}=\ln \left(1+\varepsilon_{n}\right)
\end{gathered}
$$

and $\varepsilon_{n}$ and $\sigma_{n}$ are the engineering (nominal) strain and stress respectively.

Furthermore, Abaqus requires the input of the plastic true strains instead of the total true strains in the plastic range. The plastic true strain is defined by the following equation:

$$
\varepsilon_{p l}=\varepsilon_{t}-\varepsilon_{t e}=\varepsilon_{t}-\frac{\sigma_{t}}{E}
$$

where $\varepsilon_{t e}$ is the true elastic strain.

The constitutive model is integrated by means with a robust radial return mapping algorithm.

For the endplate joint specimens, the loading was applied in two steps. In the first step, pretension effects in the bolts caused by the tightening of each bolt were simulated by applying compressive forces to bolts. In the second step, monotonic loading was applied by assigning vertical displacements at the top of the column for the specimen $\mathrm{BC} 1$ and by vertical load at the end of the beam for the specimens J1.1, J3.1 and J4.1. For the simply supported cellular beams, the loading was applied monotonically under force control. The simulation terminates when divergence in the calculation occurs. The last increment was used to define the failure load.

To account for the large displacements (P- $\Delta$ effect), "large Displacement static analysis" was adopted. The kinematic description of the elements in nonlinear geometrical analysis is based on the updated Lagrangian formulation. Within each increment, the nonlinear equilibrium equations are solved by means of the Newton-Raphson approach.

Appropriate boundary conditions, that are consistent with the actual constraints which the specimens undergo in the test setups, were applied.

Displacements values recorded for each step load at predefined joints were used to calculate the relative joint rotation connection. Displacements values recorded for each step load at predefined joints as illustrated in Fig. 11 were used to calculate the relative joint rotation connection by the following formula used in Augusto et al [14]:

$$
\phi_{j}=\arctan \left(\frac{U_{c 1}-U_{c 2}}{h_{b}}\right)-\theta_{c}
$$

where:

$U_{c 1}$ and $U_{c 2}$ are the horizontal displacements at the reference points $C 1$ and $C 2$.

$h_{b}$ is the distance between points $\mathrm{C} 1$ and $\mathrm{C} 2$

$\theta_{c}:$ is the column elastic rotation,

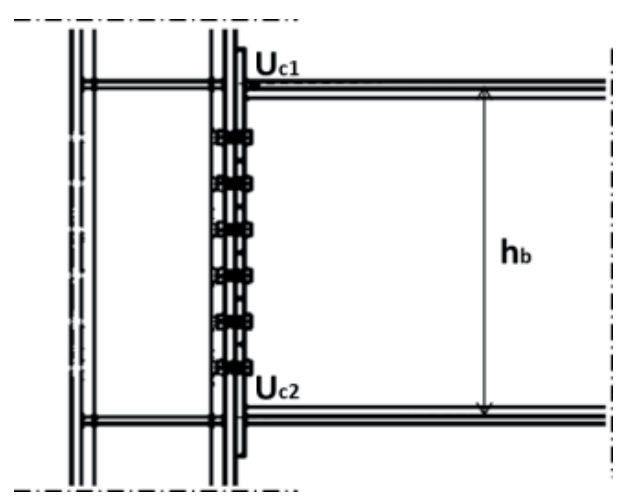

Fig. 11 Reference points and dimensions used to calculate the joint rotation

For the simple supported perforated beams, vertical displacements for different load levels were plotted at the points where deflections were recorded during the tests. 
Fig. 12 shows the comparison between the experimental moment versus rotation curves and the numerical ones for the specimen J1.1, J3.1, J4.1 and BC1. It can be seen that in general the response of the numerical moment-rotation curves agree well with the experimental ones.

In the initial stages, the experimental and the FEA moment-rotation curves are very close. Therefore, the finite element simulations can predict the initial connection stiffness $S_{j . i n i}$ with satisfactory accuracy. Though, the finite element simulation can lead to slightly more stiff connection in the elastic range when compared with the experimental results. In the nonlinear range of response, the experimental and the numerical curves are also close, but not as close as in the initial stage. For a value of rotation, the corresponding experimental bending moment is slightly higher than predicted by the 3D finite element model. Nonetheless, the FEA values are always on the safe side and the moment resistance $\mathrm{M}_{\mathrm{j} . \mathrm{Rd}}$ of the joint is accurately predicted. For the four experimental specimens, the finite elements simulations slightly over-predict the capacity of rotation. Furthermore, Fig. 13 shows that the numerical model can reproduce the deflected shape of bolted end plate connections at failure.

All the minor discrepancies observed between the experimental and the FEM curves, and principally in the nonlinear

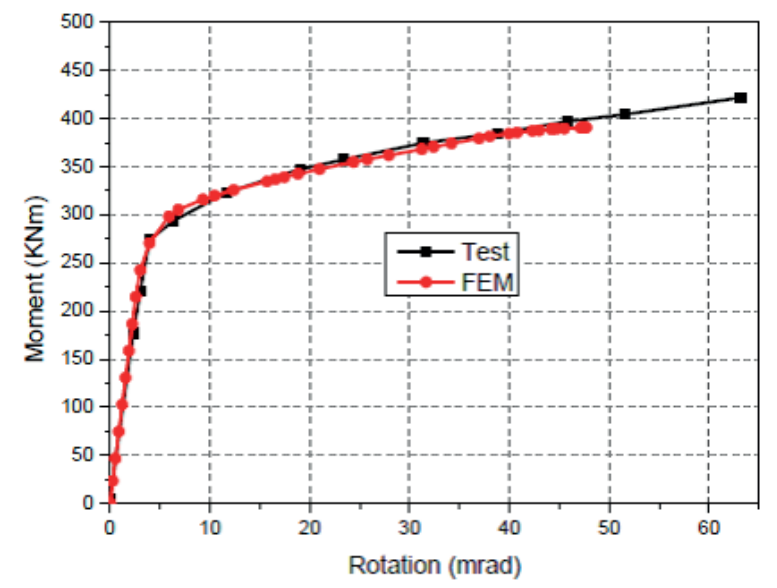

a)Specimen J1.1

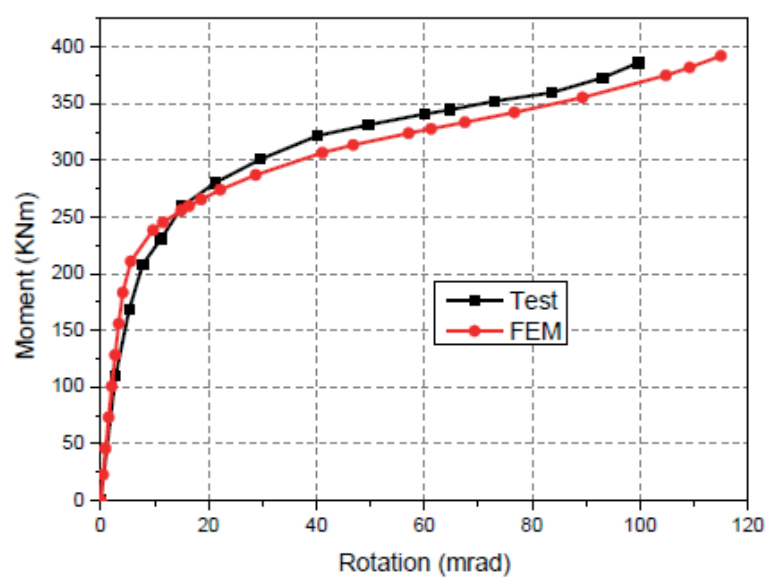

c) Specimen J4.1

Fig. 12 Comparison

Fig. 12 Comparison of the moment rotation curves between numerical and experimental data stages, are due to the numerical model simplifications such as simplified stress-strain curves and to the non-consideration of initial geometric imperfections and residual stresses.

For the purpose of this research, it can be concluded that the numerical model described herein can predict with reasonable accuracy the global behaviour of bolted end plate connections.

To evaluate the accuracy of the nonlinear finite element model results of the tested cellular beams described above, the numerical load-deflection curves are compared with the experimental ones, as illustrated in Fig. 14. It can be observed that the load-deflection curves obtained from the beam model agree reasonably well with the experimental results. The noticeable difference between the experimental and the numerical results is the ultimate deflection which is certainly due do the same simplifications mentioned previously for the connections.

\section{Effect of openings in beam webs on the characteristics of bolted end plate connections}

In this section, the joint finite element model is utilized to study the effect of circular and sinusoidal web openings on the characteristics of bolted endplate connections. Twelve end plate connections were analyzed. Four of the connection configurations, with solid web beams, as depicted in Fig. 15, were

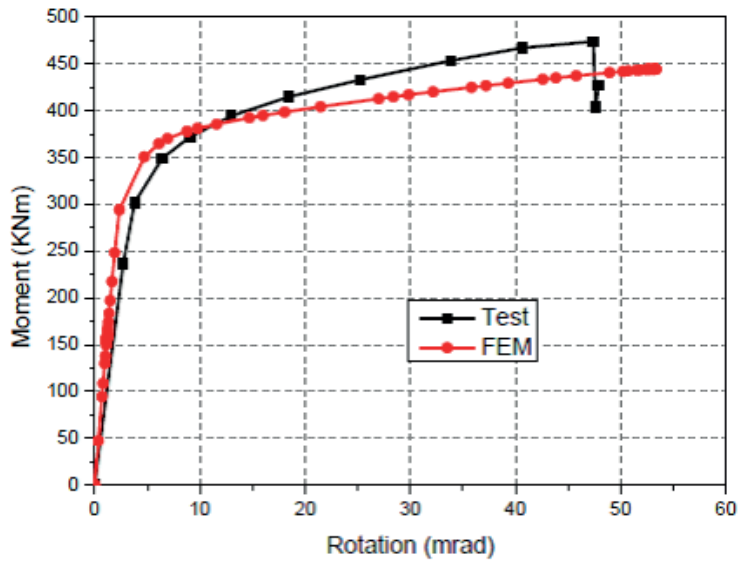

b)Specimen J3.1

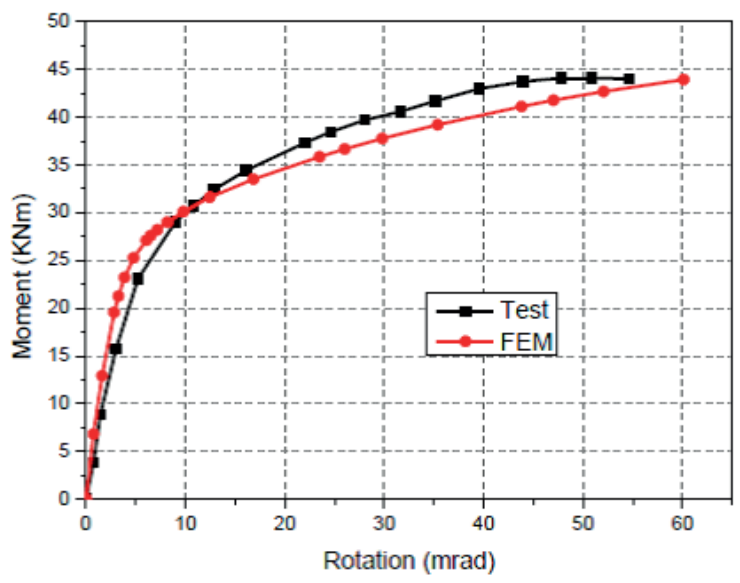

d) Specimen BC1 


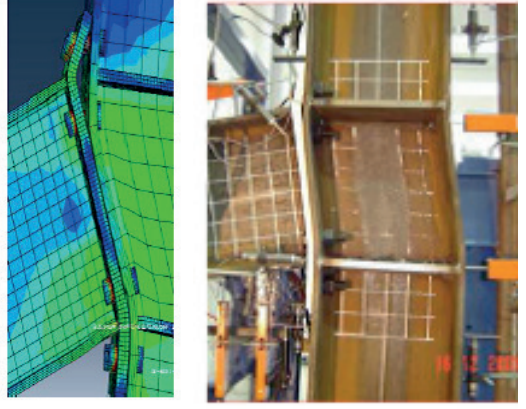

a) Specimen J1.1

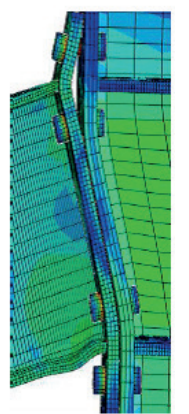

c) Specimen J4.1

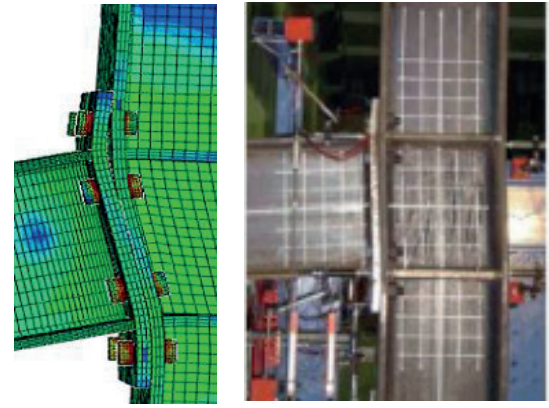

b) Specimen J3.1
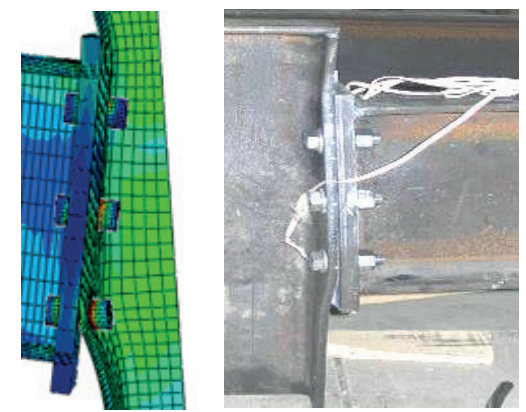

d) Specimen BC1

Fig. 13 Comparison between numerical and experimental failure modes

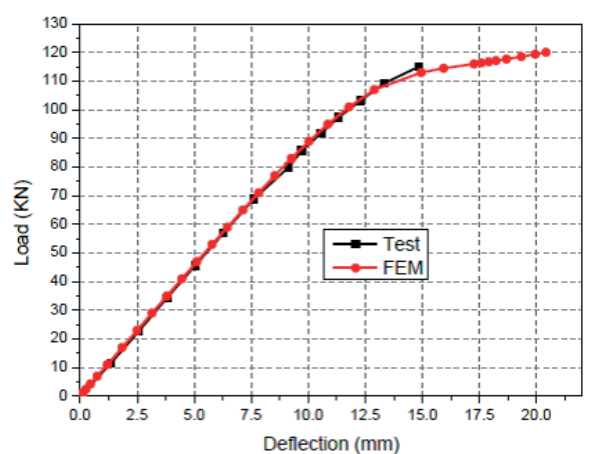

a) Specimen A1

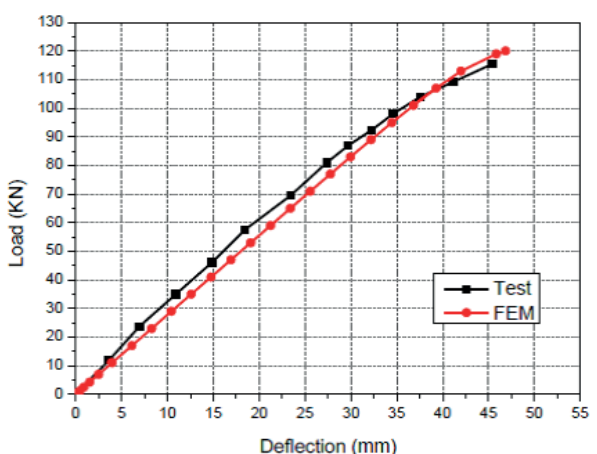

c) Specimen B2

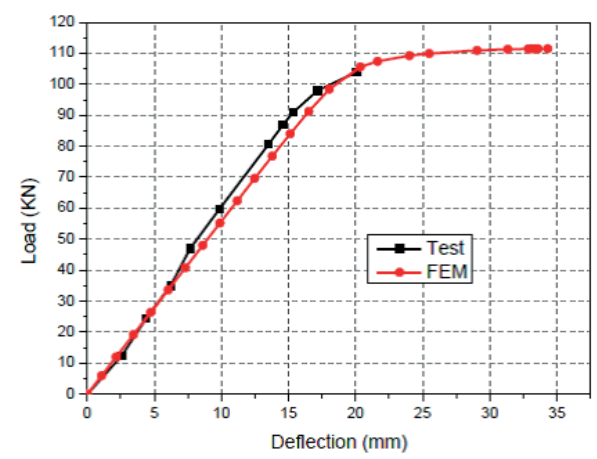

e) Specimen AS016

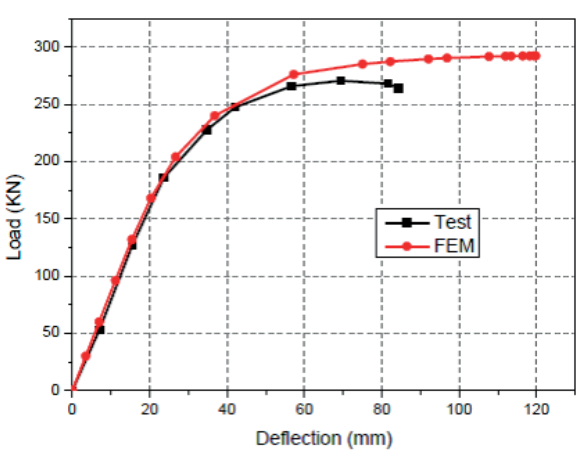

b) Specimen A2

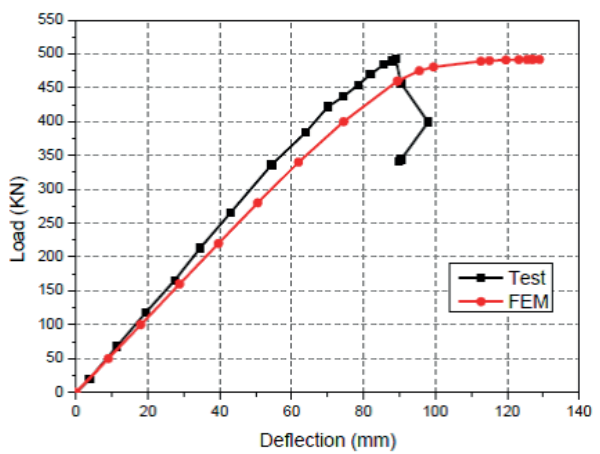

d) Specimen AS012

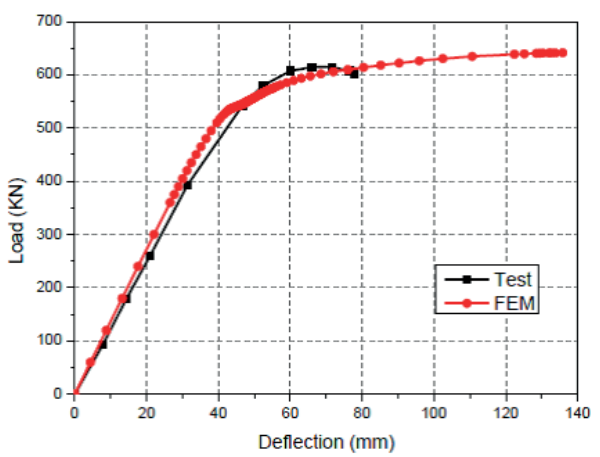

f) Specimen AS018

Fig. 14 Comparison of experimental and numerical load-deflection curves 


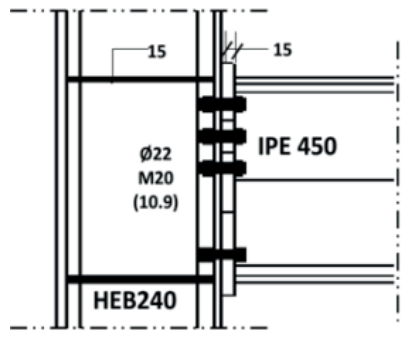

a) Joint 1
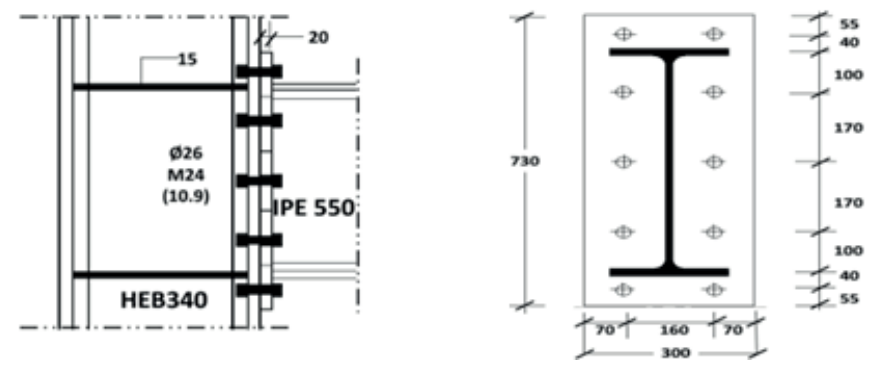

c) Joint 3
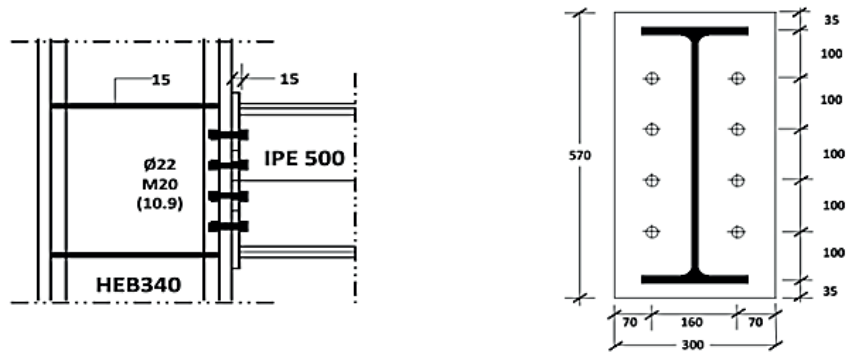

b) Joint 2

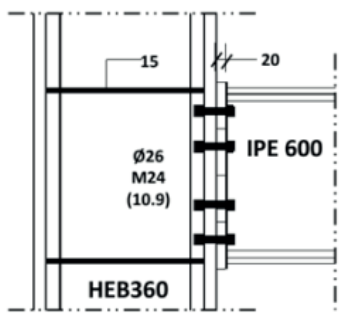

d) Joint 4

Fig. 15 Geometrical parameters of the solid beam-to-column connections
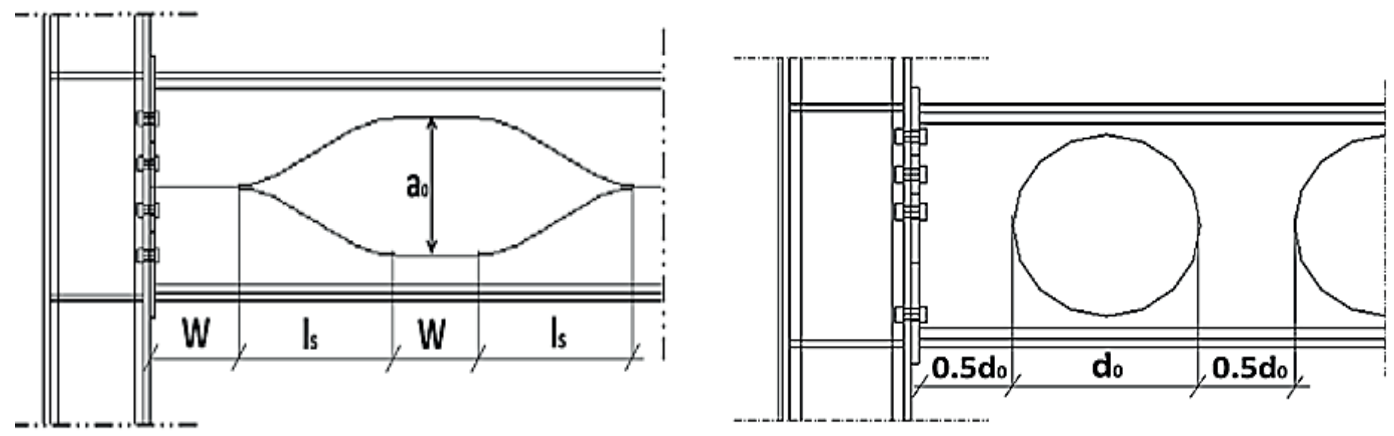

Fig. 16 Geometrical parameters of openings in the beam webs

utilized as reference specimens. The moment-rotation curve of each of the four connections is compared with two similar connections configuration but in which the solid beam is substituted with perforated beam with circular or sinusoidal web openings. Geometric limits of the openings adopted for each specimen were within the limits recommended in the Annex N of ENV 1993-1-1 [1] and the design guidelines for Angelina beams published by ArcelorMital [20]. Geometric parameters of the perforated beams adopted in the present study are shown in Fig. 16. The diameter of the circular openings $d_{0}$ is equal to $80 \%$ of the web depth. Dimensions that define the shape and the layout of the sinusoidal opening geometric parameters are as follows:

- The depth of web opening $\mathrm{a}_{0}$ to the clear height of the web ratio is 0.75

- $\mathrm{W}$ the length of the intermediate web post is equal to 250 $\mathrm{mm}$

- $\mathrm{l}_{\mathrm{s}}$ the length of the sinusoids were determined using predesign charts developed by Arcelor Mittal for non-composite roof cellular beams [20].
For comparison purposes between the characteristics of the joints with solid beams and those with perforated beams, it was assumed that the total height of a cellular beam and the solid beam are identical. The geometric configurations of the web openings were adopted in order to minimize the mechanical characteristics of the connections. This would be realized by considering the largest allowed web openings positioned as close as possible to the column face.

The dimensions of the openings in the web beams are given in table 1.

\begin{tabular}{lcccc}
\multicolumn{5}{c}{ Table 1 Dimensions of the openings in the beam webs } \\
\hline Joint & $\mathrm{d}_{0}$ & $\mathrm{a}_{0}(\mathrm{~mm})$ & $\mathrm{W}(\mathrm{mm})$ & $1_{\mathrm{s}}$ \\
\hline 1 & 284.1 & 275.2 & 488.8 & 250 \\
2 & 319.5 & 300.8 & 530.6 & 250 \\
3 & 350.7 & 359.2 & 611.6 & 250 \\
4 & 385.5 & 359.2 & 611.6 & 250 \\
\hline
\end{tabular}

Typical finite element models of the joints with perforated beams are shown in Fig. 17. 

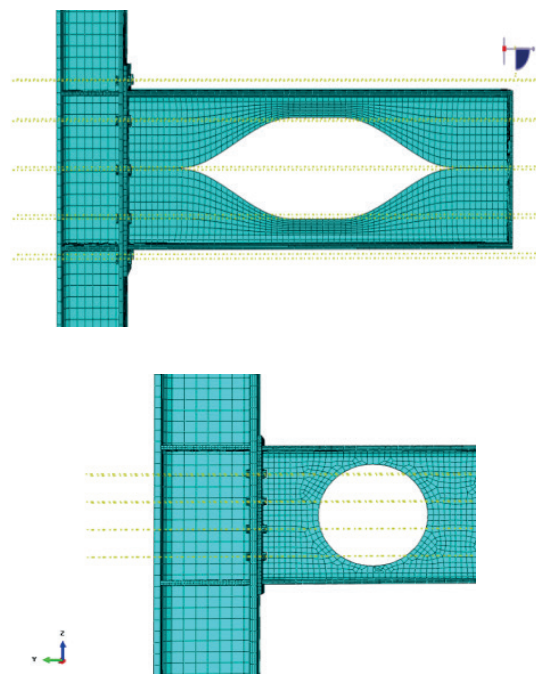

Fig. 17 Typical meshing for perforated beam models

The moment-rotation curves shown in Fig. 18 indicate clearly that both circular and sinusoidal web beam openings have little effects on the characteristics of the connection. The moment versus rotation curves of the connections with solid beams virtually coincide with those of the connections with perforated beams. However, a slight difference between the curves of the joints with perforated beams and those with solid beams is observed as the height of the beam increases.

\section{FE modeling of cellular beams connected to the columns with endplate connections \\ 5.1 Description of the models}

The finite element procedures discussed above for both endplate beam to column joints and simply supported cellular beams are extended in this section to assess the impact of various endplate connection types on the global behavior of cellular beams with circular and sinusoidal web openings.

For this purpose, numerical simulations were performed on one hundred and twenty-eight full scale one-storey onebay steel planar frame models built up from eight cellular beams, varying the beam to column connection configuration as shown in Table 2. Four of the reference cellular beams have circular openings, while the other four have sinusoidal openings. The parent section of the cellular beams and the columns are hot-rolled profiles of steel grade S235.

The geometric parameters of the cellular beams (i.e. cross section and openings) are shown in Table 3. The geometric properties of cellular beams, columns and joint components were selected and varied based upon a comprehensive practical ranges. Various end plate configurations were considered for the connection between the beam and the columns flanges: partial depth, flush, extended on both ends, stiffened or unstiffened in order to obtain joints with various rigidities and moments of resistance. Furthermore, three configurations of web panels were considered: unstiffened, stiffened with conventional longitudinal stiffeners and/or diagonal stiffeners.

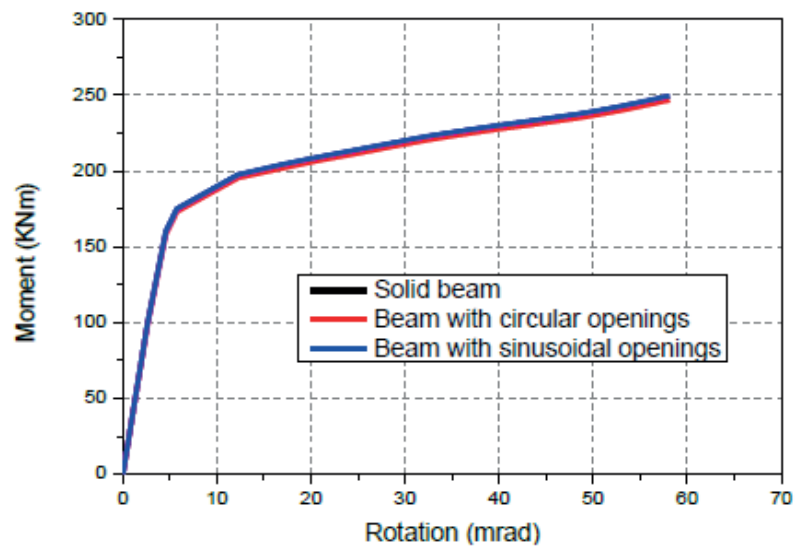

a) Joint 1

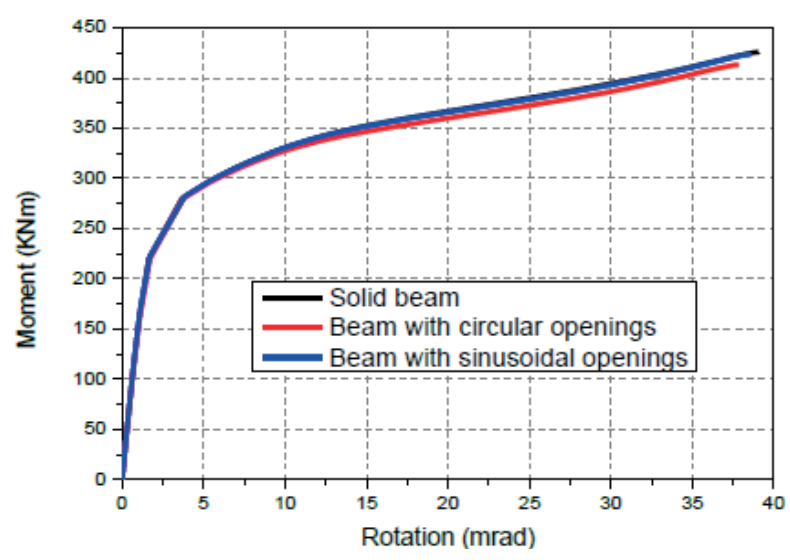

b) Joint 2

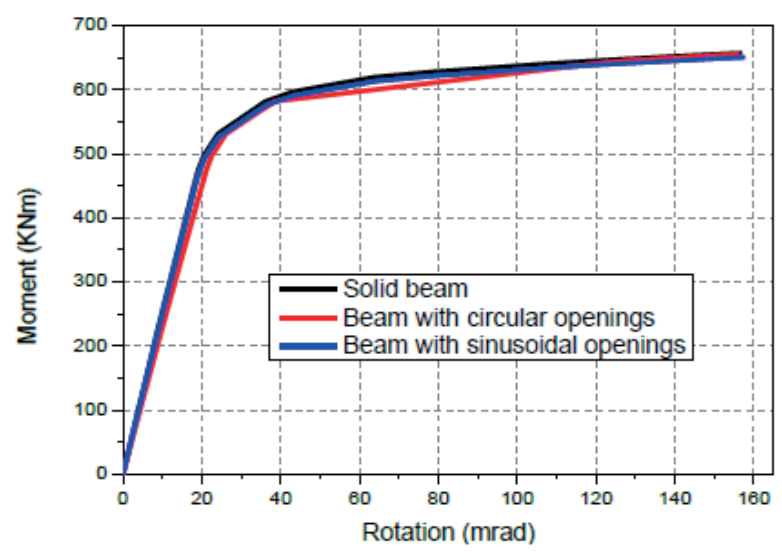

c) Joint 3

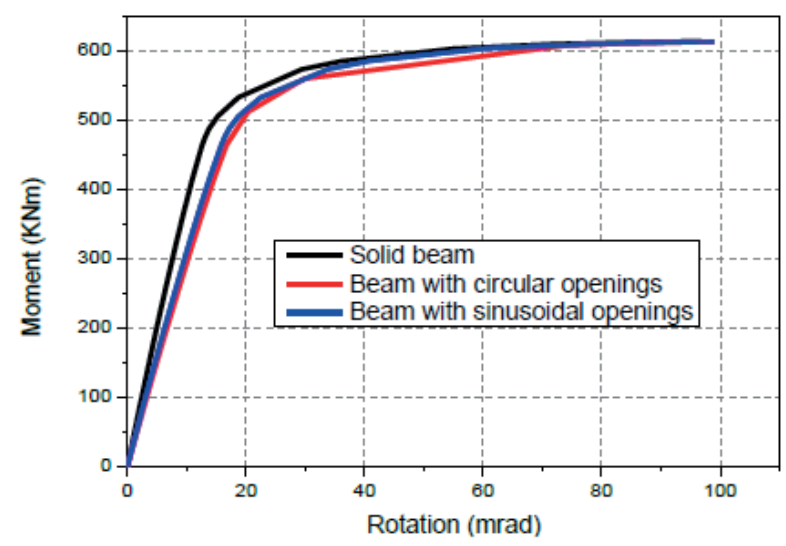

d) Joint 4

Fig. 18 Comparison of moment-rotation curves for solid beam model with perforated beam models 
For partial depth end plates, the height of the plate was taken as the half of the total beam height. Further parameters which have been varied within the studied frames are the beam and the column cross sections.

Nevertheless, a constant height of $3 \mathrm{~m}$ was adopted for all columns. Two kind of monotonic loading pattern were considered: midpoint concentrated load and uniformly distributed load. All nodes at the column bases were fully fixed to represent a fixed base. Because of symmetry, only one half of the frames were considered with appropriate boundary conditions along the plane of symmetry. A typical meshing of a full scale frame is shown in Fig. 19.

\subsection{Results and discussion}

\subsubsection{Ultimate strength}

The effects of the beam to column joint upon the global behavior of the simulated cellular beams were firstly assessed in terms of load-deflection curves at mid-span of the beams. Only selected load-deflection curves were presented in Figs 20 and 21 because they virtually follow the same trend. In these figures, It can be noticed that the load-deflection curves of the simply supported cellular beams and those of the cellular beams connected to the column with partial depth connections are almost superimposed. The behavior of the cellular beams connected to the column with partial endplate connection

Table 2 Geometry and type of the investigated frame joints

\begin{tabular}{|c|c|c|c|c|c|c|}
\hline Specimens & $\begin{array}{l}\text { Parent beam } \\
\text { section }\end{array}$ & Type of end plate & $\begin{array}{l}\text { End plate } \\
\mathrm{t}_{\mathrm{p}}(\mathrm{mm})\end{array}$ & $\begin{array}{c}\text { Rib Stiffener } t_{r s} \\
(\mathrm{~mm})\end{array}$ & $\begin{array}{c}\text { Horizontal stiffeners } \\
\mathrm{t}_{\mathrm{hs}}(\mathrm{mm})\end{array}$ & $\begin{array}{c}\text { Diagonal stiffener } \\
\mathrm{T}_{\mathrm{ds}}(\mathrm{mm})\end{array}$ \\
\hline & IPE 300 & & & & & \\
\hline FPD300 & & Partial depth & 10 & - & - & - \\
\hline FF300 & & Flush & 10 & - & - & - \\
\hline FE300 & & Extended & 10 & - & - & - \\
\hline FER300 & & Extended & 10 & 10 & - & - \\
\hline FEHD300 & & Extended & 10 & - & 10 & 10 \\
\hline FEH300 & & Extended & 10 & - & 10 & - \\
\hline FEHDR300 & & Extended & 10 & 10 & 10 & 10 \\
\hline \multirow[t]{2}{*}{ SS300 } & & - & - & - & - & - \\
\hline & IPE 450 & & & & & - \\
\hline FPD450 & & Partial depth & 15 & - & - & - \\
\hline FF450 & & Flush & 15 & - & - & - \\
\hline FE450 & & Extended & 15 & - & - & - \\
\hline FER450 & & Extended & 15 & 15 & - & 20 \\
\hline FEHD450 & & Extended & 15 & - & 20 & - \\
\hline FEH450 & & Extended & 15 & - & 20 & 20 \\
\hline FEHDR450 & & Extended & 15 & 15 & 20 & - \\
\hline \multirow[t]{2}{*}{$\mathrm{SS} 450$} & & - & - & - & - & \\
\hline & IPE 500 & & & & & - \\
\hline FPD500 & & Partial depth & 20 & - & - & - \\
\hline FF500 & & Flush & 20 & - & - & - \\
\hline FE500 & & Extended & 20 & - & - & - \\
\hline FER500 & & Extended & 20 & 15 & - & 20 \\
\hline FEHD500 & & Extended & 20 & - & 20 & - \\
\hline FEH500 & & Extended & 20 & - & 20 & 20 \\
\hline FEHDR500 & & Extended & 20 & 15 & 20 & - \\
\hline \multirow[t]{2}{*}{ SS500 } & & - & & - & - & \\
\hline & IPE 550 & & & & & \\
\hline FPD550 & & Partial depth & 20 & - & - & - \\
\hline FF550 & & Flush & 20 & - & - & - \\
\hline FE550 & & Extended & 20 & - & - & - \\
\hline FER550 & & Extended & 20 & 20 & - & - \\
\hline FEHD550 & & Extended & 20 & - & 20 & 20 \\
\hline FEH550 & & Extended & 20 & - & 20 & - \\
\hline FEHDR550 & & Extended & 20 & 20 & 20 & 20 \\
\hline SS550 & & - & - & - & - & - \\
\hline
\end{tabular}

Table 3 Table Geometrical parameters of the analyzed frames

\begin{tabular}{|c|c|c|c|c|c|c|c|}
\hline \multirow[t]{2}{*}{ Beam Profile } & \multirow[t]{2}{*}{ Column Profile } & \multirow[t]{2}{*}{ Span (m) } & \multicolumn{2}{|c|}{ Circular openings } & \multicolumn{2}{|c|}{ Sinusoidal openings } & \multirow[b]{2}{*}{ Is } \\
\hline & & & $\mathrm{D}$ & $\mathrm{W}$ & $\mathrm{a}$ & W & \\
\hline IPE 300 & HEA 200 & 14 & 350 & 417.2 & 417.2 & 250 & 691.3 \\
\hline IPE 450 & HEB 240 & 22 & 475 & 677.6 & 677.6 & 250 & 1072.2 \\
\hline IPE 500 & HEB340 & 24 & 525 & 772 & 772 & 250 & 1204.3 \\
\hline IPE 550 & HEB340 & 24 & 580 & 772 & 772 & 250 & 1204.3 \\
\hline
\end{tabular}


is almost identical to that of the simply supported ones. For this reason, this type of connection is usually classified as nominally pinned which validates the numerical model used in this study.

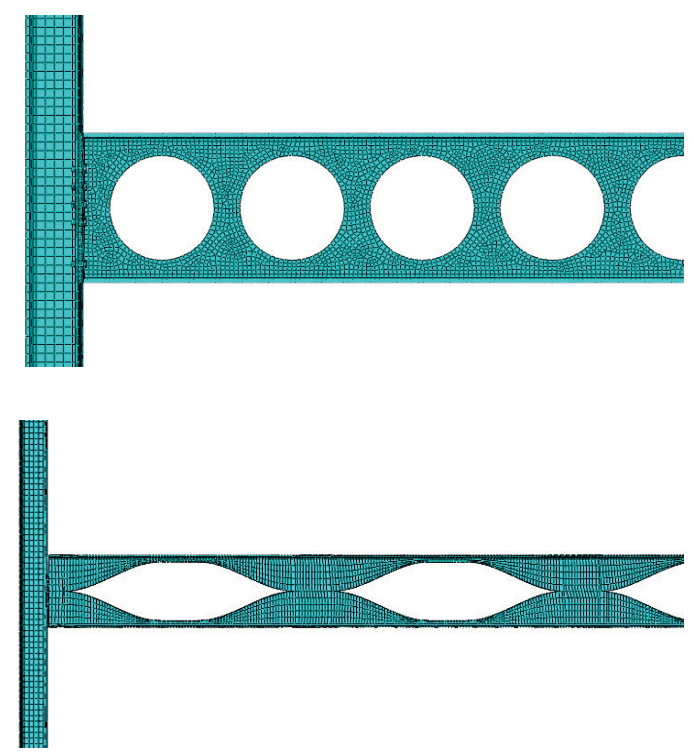

Fig. 19 Typical meshing of cellular beams connected to the columns with flush endplate connections

The load-deflection curves show that the beams connected to the columns with flush endplates and those connected to the columns with different types of extended endplate configurations (with or without endplate stiffeners, with or without column stiffeners) are almost identical. The use of extended endplate, stiffened end plate, or stiffeners in column web panel does improve neither the ultimate load capacity nor the deflection at service or ultimate loads when compared to the cellular beams connected to the columns with flush endplate connections. It was also observed that for a number of the considered cellular beams using flush endplate connections can considerably increase their stiffness at service load levels. The bar plots shown in Figs 22 and 23 shows the ultimate loads obtained for the simply supported cellular beams and the cellular beams connected to the columns with various endplate connections and in which a number of the column web panels are stiffened by both longitudinal and/or diagonal stiffeners. Joints with column web panels stiffened by both longitudinal and diagonal stiffeners possess the maximum rigidity and moment resistance among those considered in this study. The profiles indicated in these figures are the original parent sections of the cellular beams. It can be observed from these figures that the use of flush endplate will improve significantly the ultimate load and deflection of the cellular beams when compared to the simply supported ones. It is clear that this strength improvement illustrates the semi-continuous behavior of the cellular beams connected to the column with flush endplate connections. The increase in the ultimate failure load varies between :

1). $315 \%$ and $455 \%$ for cellular beams with circular openings subjected to uniformly distributed load

2). $227 \%$ and $489 \%$ for cellular beams with circular openings subjected to mid-span concentrated load

3). $374 \%$ and $624 \%$ for cellular beams with sinusoidal openings subjected to uniformly distributed load

4). $339 \%$ and $538 \%$ for cellular beams with sinusoidal openings subjected to mid-span concentrated load.
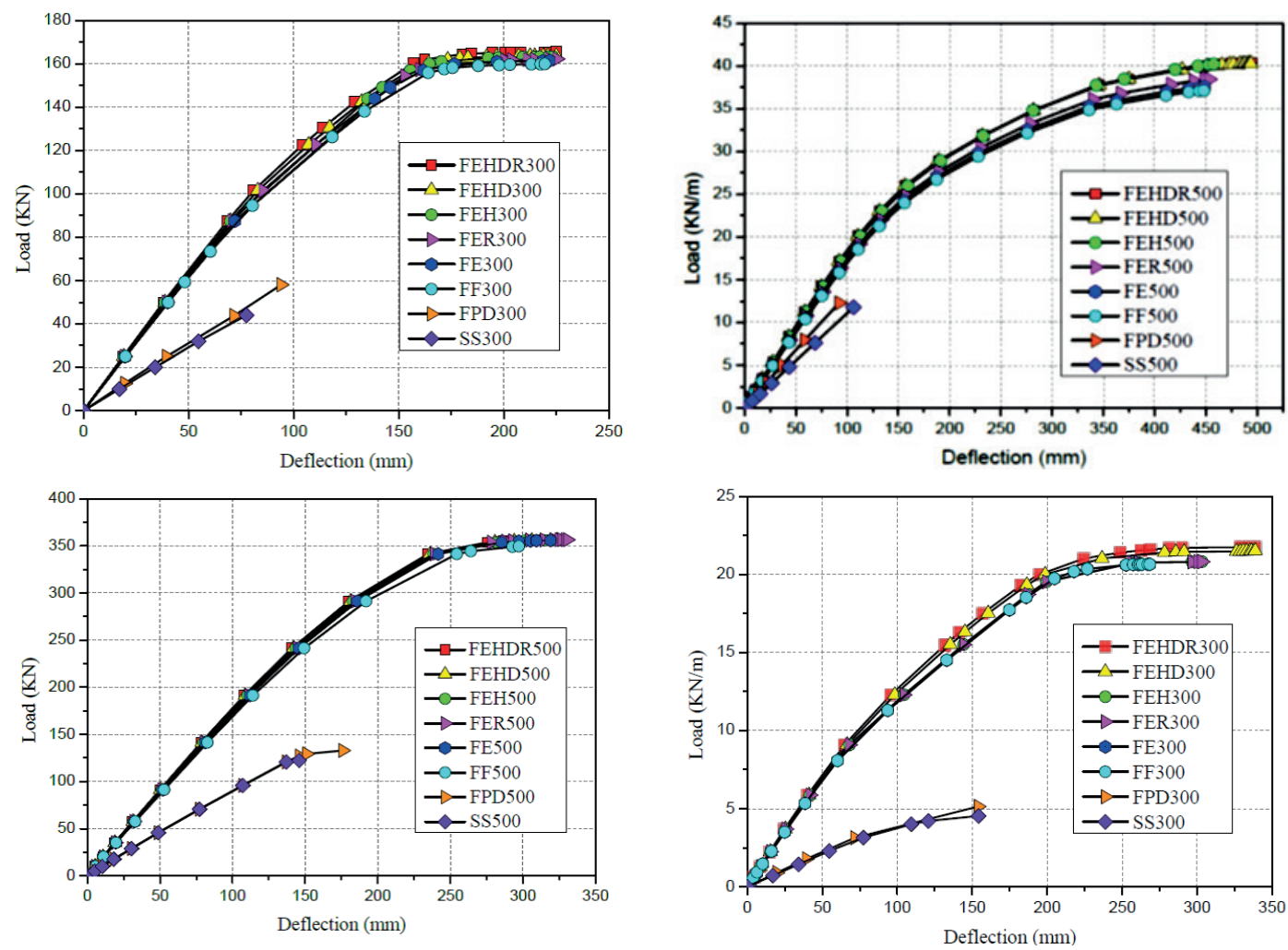

Fig. 20 Typical load-mid-span deflection curves of a selection of full scale cellular beams with circular openings and for various types of beam to column connections 

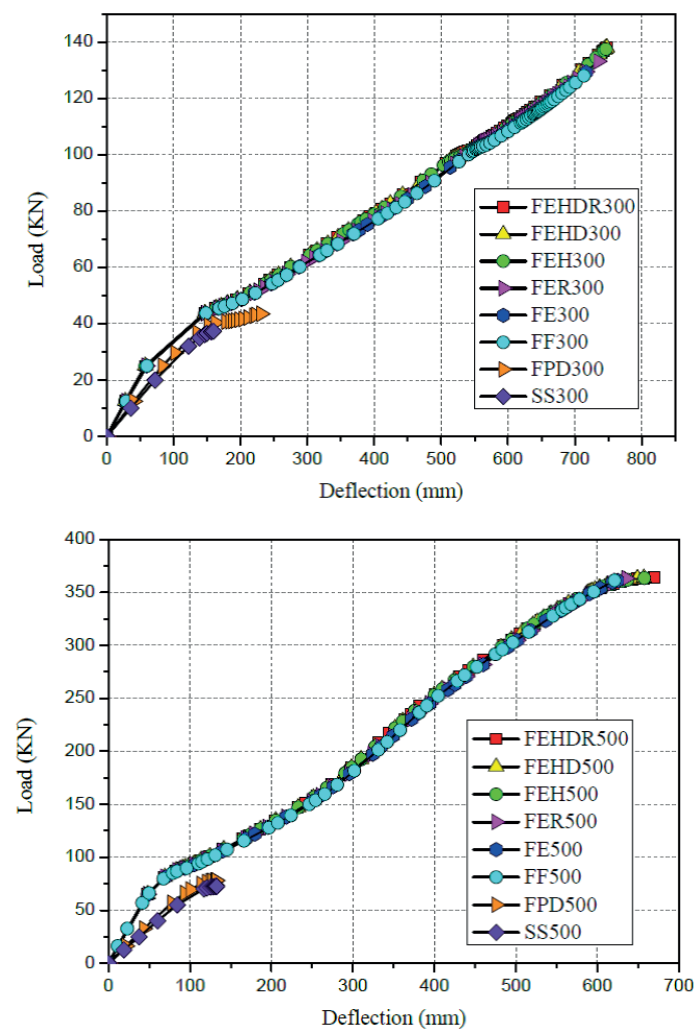

Fig. 21 Typical load-mid-span deflection curves of a selection of full scale cellular beams with sinusoidal openings and for various beam to column connections

The increase in deflection at failure load varies between:

1) $174 \%$ and $642 \%$ for cellular beams with circular openings subjected to uniformly distributed load

2) $203 \%$ and $393 \%$ for cellular beams with circular openings subjected to mid-span concentrated load

3) $156 \%$ and $466 \%$ for cellular beams with sinusoidal openings subjected to uniformly distributed load

4) $326 \%$ and $468 \%$ for cellular beams with sinusoidal openings subjected to mid-span concentrated load.

These results also show that the percentage increases in both ultimate load and maximum deflection change significantly with the geometry of the cellular beams and the type of loading. The values of the ultimate loads and maximum deflections obtained from the numerical simulations are widely scattered limiting the possibility of predicting accurately the increase in strength of cellular beams connected to the columns with flush end plates when compared to the simply supported one

\subsubsection{Failure Modes}

In this study, the yield criterion is used to predict the failure modes of cellular beams. Failure mechanisms associated with instabilities are not considered. Like the von Mises stresses, the equivalent plastic strains (PEEQ in ABAQUS) at integral points are scalar values that are often used to define the yield surface size of isotropic ductile materials such as metals. Figs. 24 and 25 show the surface plots of the equivalent plastic strain of the two cellular beams with circular and sinusoidal openings FPD500 when subjected to uniformly distributed load at failure. All the elements that exhibit plastic strain are shown
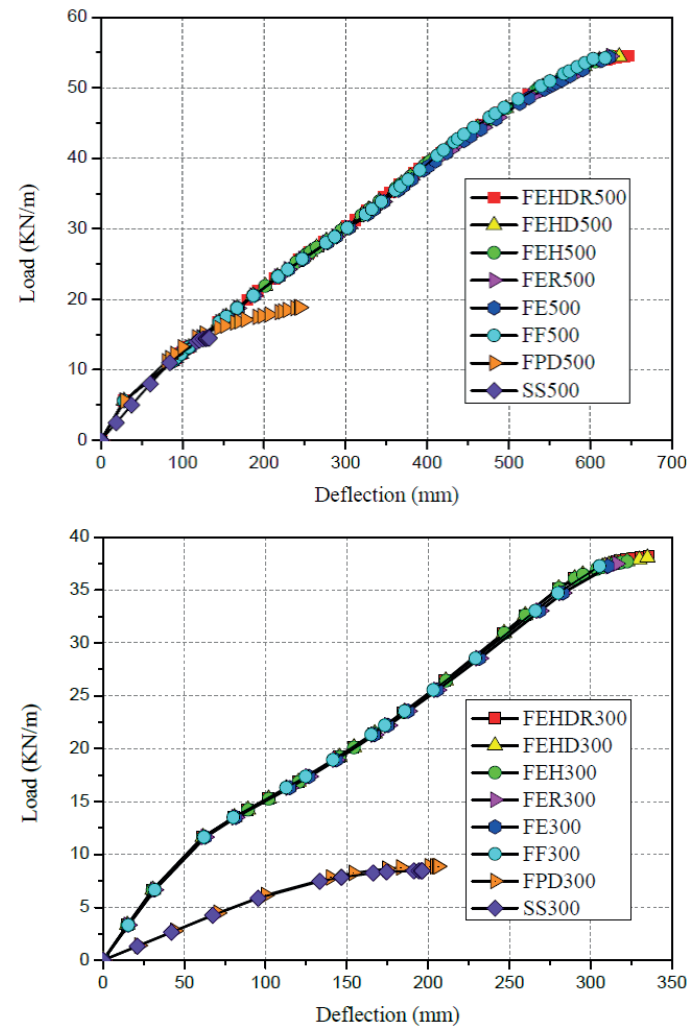

as red in the contours. Plastic strains are observed around the opening and the joint.

The two specimens demonstrated high plastic deformations around the openings and the joint. For cellular beams with circular openings, in the regions subjected to high global bending moment and low global shear force (Fig. 24(b)), it can be shown that the three sections above and below the openings are fully or partially yielded in compression and in tension. The plastic zones above and below the openings expanded to the upper and the lower flanges as the global moment is increased. As the global moment decreases and the global shear increases, four plastic zones appears at inclined cross sections of the tee web situated at the second opening as can be shown in figure 24(a). A similar yield pattern is also revealed around the sinusoidal openings as illustrated in figure 25(a). At the first circular opening from the support, the yield zones overlap due to a higher global shear force and interaction effects between the first opening and the joint. Those yield patterns are observed in simply supported cellular beams and they lead to the conventional flexural and Vierendeel mechanisms. Because Vierendeel mechanism is likely to occur in cellular beams with large web openings, four plastic hinges are formed at each corner of all sinusoidal openings including those subjected to low global shear force as depicted in figure 25(a). Yielding is also observed at the mid-height of the web-post between two adjacent sinusoidal openings. This type of yielding pattern may lead to a mechanism provoked by the fracture of the mid-depth weld joint. This failure mode is likely to occur for short horizontal joints of the web-post when they are subjected to high horizontal shear. 

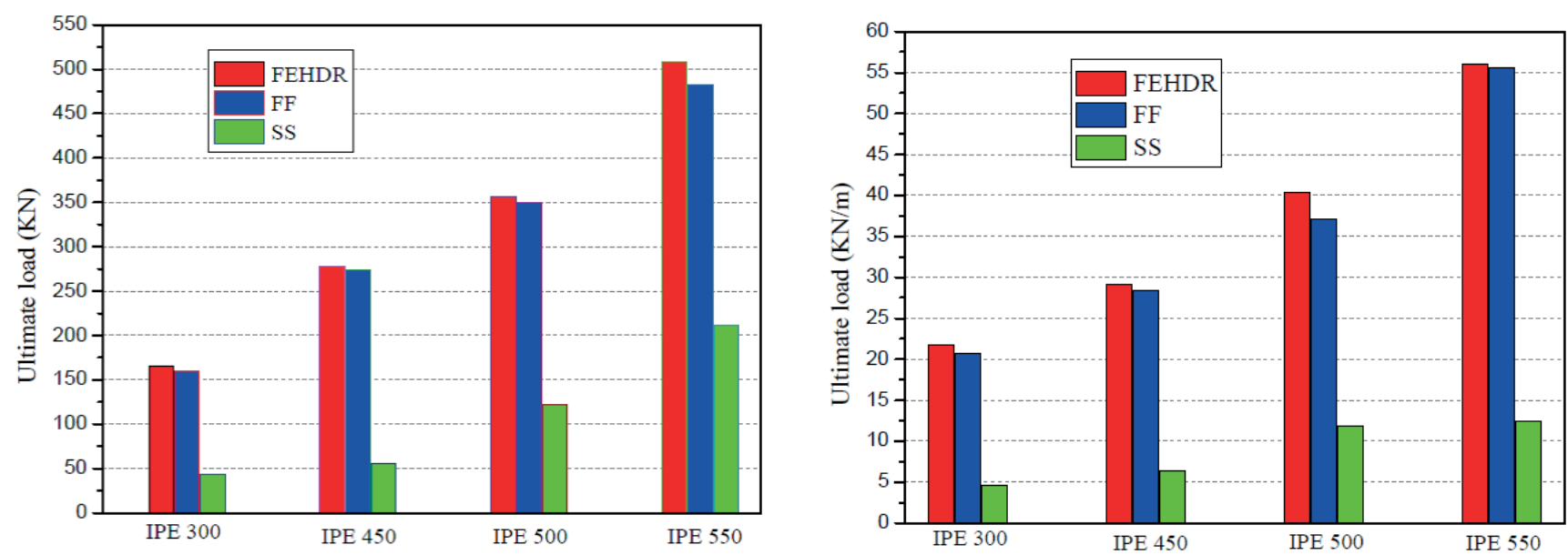

Fig. 22 Comparison of ultimate loads of cellular beams with circular openings and various types of beam to column connections
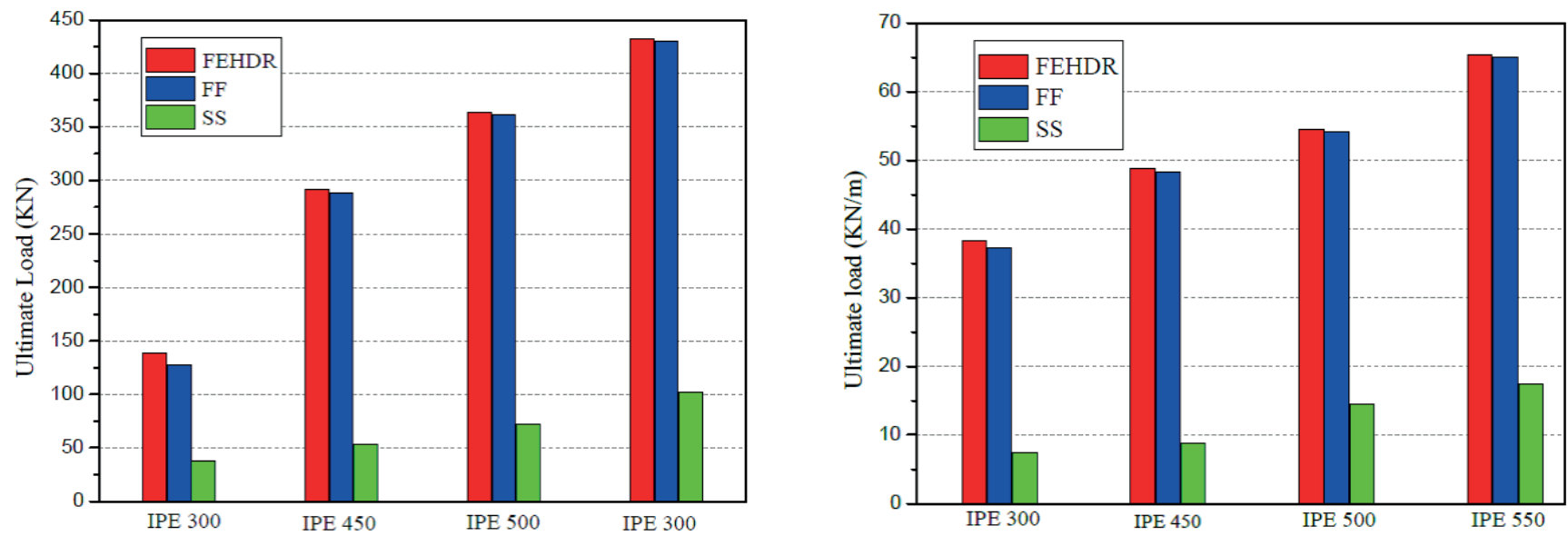

Fig. 23 Comparison of ultimate loads of cellular beams with sinusoidal openings and various types of beam to column connections
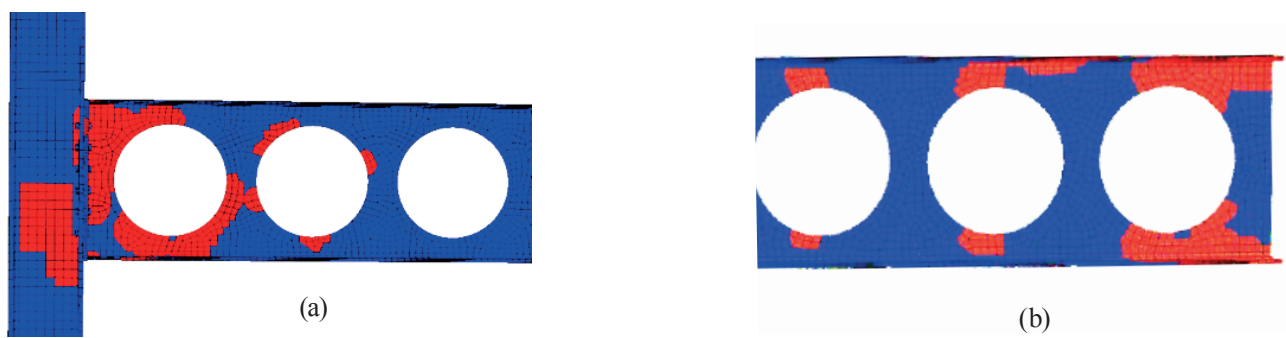

(b)

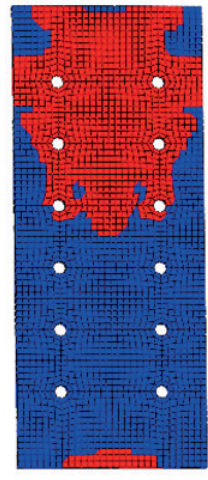

(c)
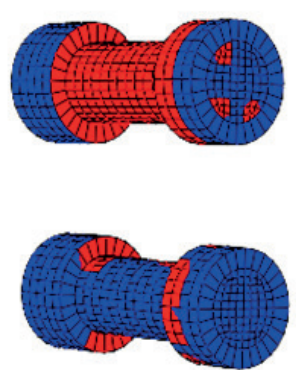

(d)

Fig. 24 Plastic equivalent strain (PEEQ) contour plot of specimen FPD500 with circular openings under uniformly distributed load at failure 


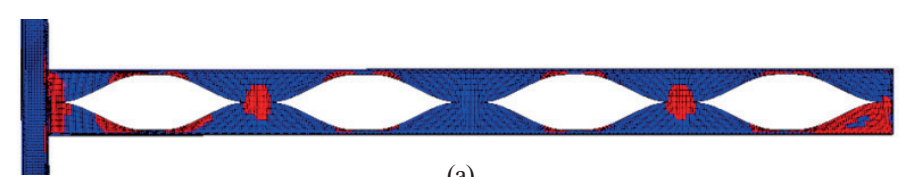

(a)
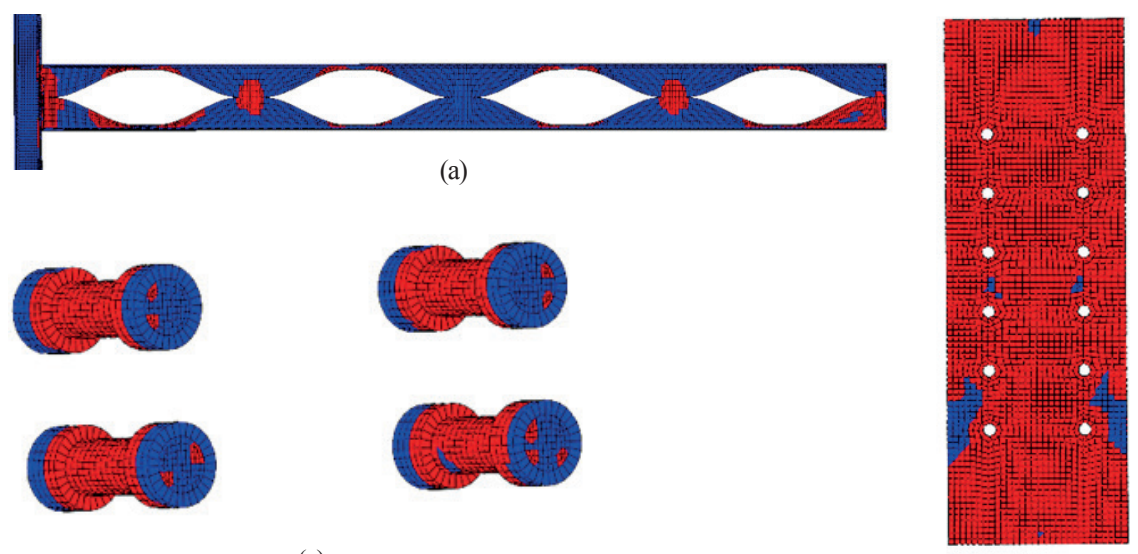

(c)

(b)

Fig. 25 Plastic equivalent strain (PEEQ) contour plot of specimen FPD500 with sinusoidal openings under uniformly distributed load

Furthermore, the numerical results have also shown that at failure, all the components of the connection (endplate, bolts and shear panel) and the end-posts of all models exhibit fully or partially plastic deformations as illustrated in Figs. 24 and 25 . The fact that using more resistant joints does not improve the ultimate load of the cellular beams indicates that the cellular beams fail before the joints develop their full plastic resistance or their maximum plastic rotations or they fail simultaneously. Therefore, the flush endplates used in this study can be classified as full strength joint.

According to EN-1993-1-8 [5], the beam to column endplate connections behave elastically for up to at least $2 / 3$ of its moment resistance. Therefore, it can be concluded that at failure, the beam end moments $M_{E d}$ should satisfy:

$$
M_{j, \text { ela }} \leq M_{\text {supp }} \leq M_{j, R d}
$$

where:

$M_{j, \text { ela }}$ is the maximum elastic moment of the connection

$M_{j, R d}$ is the moment resistance of the connection.

\subsubsection{Moment distribution at failure}

In this section, the numerical results obtained above are used to evaluate the moment at the support and the mid-span cross sections in the cellular beams connected to the columns with flush endplate at failure. In order to achieve this objective, the following assumption has been assumed:

$$
2 M_{j, R d} / 3 \leq M_{\text {supp }} \leq M_{j, R d}
$$

This assumption was verified for the cellular beams connected to the column with flush end plates considered in this study.

At all stages of loading, the sum of the absolute values of the mid-span and the supports moments must satisfy the following equilibrium equation:

$$
M_{\text {supp }}+M_{\text {span }}=M_{0}
$$

where:

$M_{0}$ is the maximum positive moment of a simply supported beam having the same span and subjected to the same load as the real beam.

Thus, if the bending moment transferred by the connection is known, the mid-span moment would be calculated from:

$$
M_{\text {span }}=M_{0}-M_{\text {supp }}
$$

The mid-span moment of the simply supported beam due to the uniformly distributed load $q_{u}$ or the mid-span concentrated load $Q_{u}$ at failure are respectively, $\frac{q_{u l^{2}}}{8}$ and $\frac{Q_{u} L}{4}$.

The ultimate loads $q_{u}$ and $Q_{u}$ are obtained from the above numerical analyses.

The ratio $\lambda$ of the predicted hogging to sagging moments at failure for the cellular beams connected to the columns with flush endplate subjected to mid-span concentrated load and uniformly distributed load are presented in table 3 and 4 , respectively. The moment resistant of each joint configuration was calculated using commercial software developed, specifically for steel joint design, by Autodesk in accordance with the component method of EN 1993-1-8 [5]. The ratio of hogging to sagging moments at failure was calculated by considering for the support moment the two extreme values, adopted by EN 1993-1-8 [5], which may be experienced by endplate joints beyond the elastic limit, $M_{\text {supp }}=2 / 3 M_{j, R d}$ and $M_{j, R d}$.It can be observed that the ratios $\lambda$ of hogging to sagging moments at failure are quite different, depending on the geometrical parameters of the cellular beams and the type of the applied load.

Equation (7) and the numerical results presented in Table 4 and 5 can be used to estimate the ultimate load capacity of cellular beams with large closely spaced openings.

For cellular beams subjected to uniformly distributed load:

$$
q_{u}=\frac{8(1+\lambda)}{\lambda 1^{2}} M_{\text {supp }}
$$

If we assume $M_{\text {supp }}=\frac{2 M_{j, R d}}{3}$, hence

$0.11 \leq \lambda \leq 0.16$ for cellular beams with circular openings $0.06 \leq \lambda \leq 0.12$ for cellular beams with sinusoidal openings 
If we assume $M_{\text {supp }}=M_{j, R d}$

$0.15 \leq \lambda \leq 0.20$ for cellular beams with circular openings

$0.09 \leq \lambda \leq 0.16$ for cellular beams with sinusoidal openings

For cellular beams subjected to mid-span concentrated load:

$$
q_{u}=\frac{4(1+\lambda)}{\lambda 1} M_{\text {supp }}
$$

If we assume $M_{\text {supp }}=\frac{2 M_{j, R d}}{3}$, hence

$0.11 \leq \lambda \leq 0.20$ for cellular beams with circular openings

$0.15 \leq \lambda \leq 0.22$ for cellular beams with sinusoidal openings

If we assume $M_{\text {supp }}=M_{j, R d}$

$0.15 \leq \lambda \leq 0.24$ for cellular beams with circular openings

$0.2 \leq \lambda \leq 0.27$ for cellular beams with sinusoidal openings

However, experimental and more numerical investigations are required to determine more precisely the values of the hogging to sagging coefficient in terms of the joint and the cellular beams properties.

\section{Conclusions}

Cellular beams have always been designed as nominally pinned to the columns. To improve the load capacity of cellular beams, connections which have some degree of rotational rigidity can be used instead of the conventional simple connections. In this paper, numerical investigations have been conducted to study up to failure the behavior of cellular beams connected to the columns with various configurations of bolted endplate connections. Simulations were also performed on beam to column steel joints in order to assess the effect of web openings on the behavior of endplate connections. From the numerical results of this investigation, the following conclusions can be drawn:

(1) Large circular and sinusoidal web beam openings located close to the beam to column joint have little effects on the characteristics of the connection. Thus, the characteristics of the endplate connections with perforated beams can be de calculated by the same methods used for joints with solid beams.

(2) Cellular beams connected to the column with partial endplate connection can be designed as simply supported.

(3) The adoption of flush endplate or extended endplate cellular beam to column joints improves significantly the ultimate load and deflection of cellular beams when compared to simply supported ones.

(4) The adoption of extended endplate cellular beam to column joints instead of flush endplate does not improve either the ultimate load or the stiffness of cellular beams.

Table 4 Predicted ratio of hogging to sagging moments for cellular beams subjected to midspan concentrated load at failure

\begin{tabular}{|c|c|c|c|c|c|c|}
\hline \multirow[t]{2}{*}{ Beam designation } & \multirow[t]{2}{*}{$M_{0}(\mathrm{kN} . \mathrm{m})$} & \multirow[t]{2}{*}{$M_{j, R d}(\mathrm{kN} . \mathrm{m})$} & \multicolumn{2}{|c|}{$M_{\text {span }}(\mathrm{kN} . \mathrm{m})$} & \multicolumn{2}{|c|}{$\lambda=M_{\text {supp }} / M_{\text {span }}(\mathrm{kN} . \mathrm{m})$} \\
\hline & & & $M_{0}-2 / 3 M_{j, R d}$ & $M_{0}-M_{j, R d}$ & $2 / 3 M_{j, R d} / M_{s p a n}$ & $M_{j, R d} / M_{s p a n}$ \\
\hline \multicolumn{7}{|l|}{ FF300 } \\
\hline (1) & 560 & 86.68 & 502.21 & 473.32 & 0.11 & 0.15 \\
\hline (2) & 480.96 & 96.88 & 416.37 & 384.08 & 0.15 & 0.20 \\
\hline \multicolumn{7}{|l|}{ FF400 } \\
\hline (1) & 1506.12 & 258.24 & 1333.96 & 1247.88 & 0.13 & 0.17 \\
\hline (2) & 1471.25 & 318.88 & 1258.66 & 1152.37 & 0.17 & 0.21 \\
\hline \multicolumn{7}{|l|}{ FF450 } \\
\hline (1) & 2009.62 & 494.55 & 1679.92 & 1515.07 & 0.20 & 0.24 \\
\hline (2) & 2088 & 571.66 & 1706.89 & 1516.34 & 0.22 & 0.27 \\
\hline \multicolumn{7}{|l|}{ FF550 } \\
\hline (1) & 2886 & 608.51 & 2480.32 & 2277.49 & 0.16 & 0.21 \\
\hline (2) & 2465 & 641.64 & 2037.24 & 1823.36 & 0.20 & 0.26 \\
\hline
\end{tabular}

(1) Cellular beams with circular openings

(2) Cellular beams with sinusoidal openings

Table 5 Predicted ratio of hogging to sagging moments for cellular beams subjected to uniformly distributed load at failure

\begin{tabular}{|c|c|c|c|c|c|c|}
\hline \multirow[t]{2}{*}{ Beam designation } & \multirow[t]{2}{*}{$M_{0}(\mathrm{kN} . \mathrm{m})$} & \multirow[t]{2}{*}{$M_{j, R d}(\mathrm{kN} . \mathrm{m})$} & \multicolumn{2}{|c|}{$M_{\text {span }}(\mathrm{kN} . \mathrm{m})$} & \multicolumn{2}{|c|}{$\lambda=M_{\text {supp }} / M_{\text {span }}(\mathrm{kN} . \mathrm{m})$} \\
\hline & & & $M_{0}-2 / 3 M_{j, R d}$ & $M_{0}-M_{j, R d}$ & $2 / 3 M_{j, R d} / M_{s p a n}$ & $M_{j, R d} / M_{s p a n}$ \\
\hline \multicolumn{7}{|l|}{ FF300 } \\
\hline (1) & 502.25 & 86.68 & 444.46 & 415.57 & 0.13 & 0.17 \\
\hline (2) & 1058.91 & 96.88 & 994.32 & 962.03 & 0.06 & 0.09 \\
\hline \multicolumn{7}{|l|}{ FF400 } \\
\hline (1) & 1721.22 & 258.24 & 1549.06 & 1462.98 & 0.11 & 0.15 \\
\hline (2) & 2719.14 & 318.88 & 2506.55 & 2400.25 & 0.08 & 0.12 \\
\hline \multicolumn{7}{|l|}{ FF450 } \\
\hline (1) & 2455.88 & 494.55 & 2126.18 & 1961.33 & 0.16 & 0.20 \\
\hline (2) & 3633.12 & 571.66 & 3252.01 & 3061.46 & 0.12 & 0.16 \\
\hline \multicolumn{7}{|l|}{ FF550 } \\
\hline (1) & 3600 & 608.51 & 3194.32 & 2991.49 & 0.13 & 0.17 \\
\hline (2) & 4373.2 & 641.64 & 3945.44 & 3731.56 & 0.11 & 0.15 \\
\hline
\end{tabular}

(1) Cellular beams with circular openings

(2) Cellular beams with sinusoidal openings 
(5) For a number of cases, endplate connections increase significantly the stiffness of cellular beams at service load level.

(6) Yield patterns distribution around circular and sinusoidal web openings of the partially restrained cellular beams are similar to those obtained for simply supported ones at failure

(7) Connections and the web-post between the opening and the connection experience a high yielding at failure due to interaction effects.

(8) Values of hogging to sagging ratio were proposed in order to estimate the load carrying capacity of cellular beams with large closely spaced circular and sinusoidal opening subjected to mid-span concentrated load and uniformly distributed load.

Further research work is required and especially experimental one in order to fully understand the behavior of partially restrained cellular beams.

\section{References}

[1] ENV 1993-1-1:1992/A2:1998 Eurocode 3: Part 1.1-Amendment A2, CEN, 1998.

[2] Large web openings for service integration in composite floors. Final Report for ECSC Research Contract 7210-PR-315, 2003 European Commission, EUR 21345, ISBN: 92-79-01723-3, EU Bookshop, Catalogue Number: KI-NA-21345-EN-C，2006. https://publications.europa.eu/en/ publication-detail/-/publication/a4af7d1a-b375-4aaa-855e-4e4159737fe3

[3] Sameer, S. F., Coulson, J., Dinehart, D.W. "Castellated and cellular beam design". American Institute of Steel Construction, Steel Design Guide, Series Number 31,2003(2016). https://www.scribd.com/document/353101315/ Design-Guide-31-Castellated-and-Cellular-Beam-Design

[4] Mottram, J. T., Zheng, Y. "State-of-the-art review on the design of beamto-column connections for pultruded frames". Composite Structures, 35(4), pp. 387-401. 1996. https://doi.org/10.1016/S0263-8223(96)00052-9

[5] EN 1993-1-8: Eurocode 3: Design of steel structures - Part 1-8: Design of joints [Authority: The European Union Per Regulation 305/2011, Directive 98/34/EC. 2005.

[6] Hedayat, A.A., Celikag, M. "Post-Northridge connection with modified beam end configuration to enhance strength and ductility". Journal of Constructional Steel Research, 65(7), pp. 1413-1430, 2009. https://doi. org/10.1016/j.jcsr.2009.03.007

[7] Hedayat, A. A., Celikag, M. "Fracture moment and ductility of welded connections". Proceedings of the Institution of Civil Engineers Structures and Buildings, 162(6), pp. 405-418, 2009. https://doi.org/10.1680/ stbu.2009.162.6.405

[8] Tsavdaridis, K. D., Papadopoulos, T. "A FE parametric study of RWS beam-to-column bolted connections with cellular beams". Journal of Constructional Steel Research, 116, pp. 92-113, 2016. https://doi.org/10.1016/j. jcsr.2015.08.046

[9] Wilkinson, S., Hurdman, G., Crowther, A. "A moment resisting connection for earthquake resistant structures". Journal of Constructional Steel Research,62(3), pp. 295-302, 2006. https://doi.org/10.1016/j.jcsr.2005.07.011

[10] Aschheim, M. A. "Moment-resistant structure, sustainer and method of resisting episodic loads". United State Patent, Patent number: US 6012256 A, Date of Patent: Jan, 11, 2000. http://www.google.com/patents/US6012256

[11] Weynand, K. "Sicherheits-und Wirtsschaftlichkeits- unter suchungenzuran wending nachgiebiger Anschlüsse im stahlbau". "Safety and economic investigations on the application of resistant connections in steel construction". PhD thesis. University of Aachen, Aachen, 1996. (in German).
[12] Girão Coelho, A. M., Bijlaard, F. S. K., Da silva, S. L."Experimental assessment of the ductility of extended end plate connections". Engineering Structures, 3(9), pp. 1185-1206, 2004. https://doi.org/10.1016/j.engstruct. 2000.09.001

[13] Nogueiro, P. "Cyclic Behaviour of Steel Connections". PhD Thesis, University of Coimbra, Portugal, 2009. (in Portuguese). https://bibliotecadigital. ipb.pt/handle/10198/4334

[14] Augusto, H., Da Silva, L. S., Rebelo, C., Castro, J. M. "Characterization of web panel components in double-extended bolted end-plate steel joints". Journal of Constructional Steel Research, 116, pp. 271-293, 2016. https:// doi.org/10.1016/j.jcsr.2015.08.022

[15] Abidelah, A., Bouchaïr, A., Kerdal, D. E. "Experimental and analytical behavior of bolted end-plate connections with or without stiffeners". Journal of Constructional Steel Research, 76, pp. 13-27. 2012. https://doi. org/10.1016/j.jcsr.2012.04.004

[16] Warren, J. "Ultimate load and deflection behaviour of cellular beams". MSc thesis, School of Civil Engineering, University of Natal, Durban, South Africa, 2001. http://researchspace.ukzn.ac.za/handle/10413/5272

[17] Durif, S., Bouchaïr, A., Vassart, O. "Experimental tests and numerical modeling of cellular beams with sinusoidal openings". Journal of Constructional Steel Research, 82, pp. 72-87, 2013. https://doi.org/10.1016/j. jesr.2012.12.010

[18] Durif, S., Bouchaïr, A., Vassart, O., "Experimental and numerical investigation on web-post member from cellular beams with sinusoidal openings". Engineering Structures, 59, pp. 587-598, 2014. https://doi.org/10.1016/j. engstruct.2013.11.021

[19] ABAQUS User's, Theory and Scripting Manuals, Version 6.12. ABAQUS, Inc., Dassault Systems Simulia Corp., Providence, USA, 2012.http://abaqus. software.polimi.it/v6.12/index.html

[20] ACB + Design software, ArcelorMittal. www.arcelormittal.com/sections

[21] Abolmaali, A., Matthys, J. H., Farooqi, M., Choi, Y. "Development of moment-rotation model equations for flush end-plate connections". Journal of Constructional Steel Research, 61(12), pp. 1595-1612, 2005. https://doi. org/10.1016/j.jcsr.2005.05.004

[22] Trahair, N. S., Bradford, M. A., Nethercot, D., Gadner, L. "The behaviour and design of steel structures to EC3". Taylor and Francis, 2008.

[23] Bursi, O. S., Jaspart, J. P. "Calibration of a finite element model for isolated bolted end plate steel connections". Journal of Constructional Steel Research, 44(3), pp. 225-262, 1997. https://doi.org/10.1016/S0143974X(97)00056-4

[24] Bursi, O. S., Jaspart, J. P. "Basic issues in the finite element simulation of extended end plate connections". Computers \& Structures, 69(3), pp. 361-382, 1998. https://doi.org/10.1016/S0045-7949(98)00136-9

[25] Sumner, E. A. "Unified design of extended end-plate moment connections subject to cyclic loading". PhD thesis, Virginia Polytechnic Institute and State University, USA, 2003. http://hdl.handle.net/10919/28078

[26] CEN, EN 1993-1-1. Eurocode 3: Design of Steel Structures - Part 1-1: General Rules and Rules for Buildings, European Committee for Standardization, Brussels, May 2005.

[27] Diaz, C., Victoria, M., Martí, P., Querin, O. M. "FE model of beam-to-column extended end-plate joints". Journal of Constructional Steel Research, 67(10), pp. 1578-1590, 2011. https://doi.org/10.1016/j.jcsr.2011.04.002

[28] Soltani, M. R., Bouchaïr, A., Mimoune, M. "Nonlinear FE analysis of the ultimate behaviour of steel castellated beams". Journal of Constructional Steel Research, 70, pp. 101-114, 2012. https://doi.org/10.1016/j. jcsr.2011.10.016

[29] Madjour, A., Soltani, M. R., Harkati, E., Boutagouga, D., Labed, A. "Effect of web beam openings on the mechanical behaviour of bolted end- plate Connections". 13TH Arab Structural Engineering Conference, University of Blida, Algeria, December 2015. 